\title{
M ujeres en la torre de marfil: feminización de la universidad española
}

\section{Elizabeth G. Vaquera* y Jesús M . de M igue***}

La Universidad no es una institución estátical. Cambia con el tiempo y se amolda a las estructuras de las sociedades en que existe. La expansión generalizada de la educación terciaria comienza tras la Segunda Guerra M undial (ALtBACH 1998: 347). Los países en vías de desarrollo también ven aumentar el número de estudiantes en sus universidades, aunque el ritmo de crecimiento es inferior. Los países que experimentan un aumento más pronunciado en su número de estudiantes universitarios son los que hoy conocemos como páses desarrollados. En esos países las universidades, a partir de la segunda mitad del siglo XX, pasan de ser instituciones para las élites a ser instituciones de masas, 0 incluso masificadas. El objetivo de la política actual es el de la Universidad universal. Su origen nace de la superación de las barreras que el nivel socioeconómico, género, edad, etnia, o lugar de residencia, entre otras variables, imponen en las opciones vitales de las personas para acceder a una educación postsecundaria2.

España entra en el proceso de progresiva universalización de la Universidad con algo de retraso, pero luego avanza rápidamente. Primero necesita consolidar los niveles de educación primaria y secundaria para posteriormente extender la educación universitaria. La universalización comienza con la igualación del nivel de estudiantes por género. En 1920 hay un total de 23.403 estudiantes universitarios en España, 710 de los cuales son muje res (3 por 100)3. En el año 2000 los estudiantes en las universidades españolas (públicas y privadas) son 1.587.055, siendo mujeres 845.347, es decir, 53 por 100 del total de estudiantes4. El proceso de universalización es un objetivo claro de la sociedad española, y a grandes rasgos lo está consiguiendo. No obstante, como señalan M aria Ch ARLES y Karen BradLEY, indicadores simples tales como las tasas brutas de matriculación son insuficientes para la eval uación de la posición relativa de la mujer en la educación terciaria (CH ARLES y BRADLEY, 2000). El análisis deta- llado de diversos indicadores de feminización matiza interpretaciones de unos porcentajes tan altos referentes a la participación de la mujer en educación terciaria. Eso es lo que se pretende de mostrar en el presente estudio.

Por primera vez en su historia España tiene más mujeres que varones estudiando en la universidad. El proceso de feminización de las universidades españolas se acelera durante la última década. Cada vez hay más mujeres entre el estudiantado y el profesorado, aunque todavía hay diferencias entre estos dos grupos. En la actualidad 54 por 100 de las personas que estudian una carrera universitaria son mujeres, y 59 por 100 del total de estudiantes que terminan la carrera. Hace tan sólo unas décadas eran unas proporciones impensables. Las familias matriculaban en la universidad a los hijos pero no a las hijas. Ahora se produce Io inverso. Q uizás en la actualidad la juventud tiene más libertad de decisión sobre si estudiar o no. Estudiar en la Universidad ya no es (siempre) la materialización del deseo de los padres, sino que otros factores como el mercado de trabajo y las expectativas de los propios jóvenes tienen un papel más relevante.

A pesar de que durante la carrera las mujeres ya superan la proporción de varones, el proceso de feminización no se ha completado en el doctorado, y sobre todo en el profesorado. De las personas que se doctoran en las universidades españolas 42 por 100 son mujeres, lejos de 59 por 100 que termina la carrera, 0 del 51 por 100 que comienza el doctorado. Entre el profesorado universitario, solamente una de cada tres personas es mujer (34 por 100). En el olimpo de los catedráticos apenas hay una mujer por cada diez varones. H ay universidades especializadas en mujeres (estudiantas), si bien otras son mayoritariamente masculinas como las tres politécnicas, UN ED, y la mitad de las universidades privadas. A nivel comparativo con otros países de 
Europa, España tiene una proporción de mujeres entre el alumnado universitario bastante alto, mayor por ejemplo que en Alemania (46 por 100), Holanda (48 por 100), Austria (49 por 100), o Reino Unido (50 por 100); aunque menor que Francia (55 por 100), Suecia (56 por 100), o N oruega (56 por 100).

A nivel global el proceso de feminización de la Universidad española casi ha concluido. Un análisis detallado de la situación sugiere que todavía hay posibilidades de expansión en la proporción de mujeres en ciertas carreras, sobre todo en ingenierías y a niveles más altos en la jerarquía universitaria (profesorado). M aria C H ARLES y Karen BRAD LEY (2002) analizan estas diferencias de género para doce países entre los cuales se encuentra España. Estas autoras diferencian entre segregación horizontal (por carre ras) y segregación vertical (por nivel). Estos dos niveles de análisis son los que permiten ver los procesos de discriminación de género, que son a menudo invisibles cuando sólo se analiza la proporción total de mujeres estudiando en la universidad. Las conclusiones de C harles y Bradley también sugieren que las características de la sociedad, que están vinculadas a su vez con la modernización económica y social del país, agravan la segregación y complica el camino hacia ideales igualitarios.

Algunos sociólogos argumentan que la familia tradicional está basada en la desigualdad (GID D ENS, 2000: 68). A pesar de las diferencias entre las carreras que las mujeres y los varones estudian (CharLes, y BRADLEY, 2000 y 2002, JACOBS, 1996 y 1999). Estos cambios en el nivel educativo de las mujeres van a afectar la estructura familiar acabando con formas tradicionales desiguales. La familia del siglo XXI se presenta más igualitaria. La educación juega un papel importante en esos logros. N unca en la historia de la H umanidad la mujer ha tenido un nivel similar de igualdad respecto del varón. España no es una excepción. Algunas de las universidades más prestigiosas de España ven cómo más del 60 por 100 de sus estudiantes son mujeres; es el caso de la Universidad Pompeu Fabra, y las universidades de Valencia, Santiago, Barcelona, D eusto, Complutense, las dos Autónomas (Barcelona y M adrid), incluso la más antigua de Salamanca. Si este proceso continúa no es aventurado decir que esto va a influir en cambios en la familia española (ALBERDI, 1999), y en consecuencia también la estructura social española5.

A nivel académico, las universidades se pueden feminizar en número de estudiantas y de profesoras. También en el personal administrativo y de servicios (PAS). Existe un modelo de universidad cuyo profesorado son mujeres, pero en las que los estudiantes son varones. Además de U NED, es el caso de varias universidades privadas como Europea de M adrid, Antonio de N ebrija, Alfonso $X$ el Sabio y San Pablo CEU. En el caso de las universidades politécnicas son varones tanto los profesores como los estudiantes. En las dos universidades pontificias los estudiantes son varones. Modernamente el que haya mujeres debería ser un fenómeno asociado al prestigio de la universidad pues la mujer obtiene me jores notas que el varón en las pruebas de selectividad (PAAU), y aprueba más durante la carrera. La excepción a la regla son las universidades politécnicas - de ingeniería y arquitectura - en donde los estudiantes suelen ser varones, y son enseñados por varones. Las tres universidades politécnicas de M adrid, C ataluña, y Valencia son las tres universidades con una proporción menor de estudiantes mujeres (entre 25 por 100 y 35 por 100) y menor aún de profesoras (entre 18 por 100 y 21 por 100).

La localización geográfica de la universidad es una variable útil para entender las diferencias del proceso de feminización. En España, las regiones con una proporción mayor de profesoras universitarias son Cataluña, Aragón, La Rioja y N avarra; es decir, el norte. La riqueza de la zona está altamente relacionada con su desarrollo, y éste con la entrada de la mujer en educación terciaria. Además hay que incluir en este grupo la Universidad Autónoma de M adrid y la Complutense. El sector privado muestra otra tendencia distinta: se especializa en educar varones, pero contrata como profesores a mujeres. Para que existan mujeres profesionales es preciso que existan buenas profesoras, sólo así se pueden aprender el modelo y rol apropiados. Q ue sólo haya 15 por 100 de catedráticas en España (incluyendo las de Universidad y las de Escuela Universitaria) es una barrera para el proceso de feminización de la investigación y la docencia.

La feminización de la universidad española es un fenómeno reciente que empieza por las cohortes más jóvenes de estudiantes; luego se extiende a profesores más jóvenes y con contratos más inestables. El proceso de feminización comienza por las personas que estudian la carrera (53 por 100 mujeres), sigue por las personas que terminan la carrera universitaria (59 por 100 muje res), y continúa por los estudios de doctorado (51 por 100 son mujeres), la obtención del título de doctor (42 por 100 son mujeres), el trabajo como profesoras universitarias (34 por 100 son mujeres), y al final llegar a la cátedra (menos de una de cada diez son mujeres) 6 . España está experimentando todavía el proceso de feminización progresiva de las universidades a niveles distintos. Ya no es tan cambiante a nivel de estudiantes, pero queda todavía mucho camino por recorrer a nivel de profesorado, sobre todo en estudios politécnicos. El proceso de privatización del sistema universitario español no está ayudando en esa dirección, ya que las universidades privadas (sobre todo las nuevas) educan mayoritariamente a varones.

El proceso de feminización en la educación secundaria, en la Universidad, y luego en el mercado laboral depende de un análisis más elaborado que supone la combinación de cohortes, así como de «itinerarios» personales 0 vitales diferentes. M arga M ARí-K LOSE y Anna N os realizan un estudio con ese planteamiento metodológico, ilustrando los diversos «itinerarios vitales» de las mujeres en la sociedad española actual (1999). La hipótesis es que la población no es homogénea, tampoco si se tienen en cuenta solamente las mujeres. Educación, trabajo, matrimonio, y 
fecundidad no son etapas que se organizan siempre en este orden, sino que admiten «tinerarios vitales» diferentes. La mujer, por ejemplo, está matriculándose en la universidad, retrasando el matrimonio (a veces incluso eliminándolo de su trayectoria vital) y difiriendo también la fecundidad. La situación actual en España es de una tasa de natalidad bajísima y una participación alta en estudios universitarios. La correlación parece ser clara. El paro femenino es el doble que el masculino, y así también es mucho mayor la proporción de mujeres buscando su primer empleo. Unas mujeres eligen (a veces poco voluntariamente) un itinerario, y sus hermanas quizás otro distinto. «A través del análisis de los itinerarios vitales de las mujeres se obtiene una radiografía de la estructura social y, a su vez, de los mecanismos de desigualdad social. Los itinerarios personales (que son sociales) se constituyen y se someten a la estructura social» (M ARíKLOSE y N OS, 1999: 11). El análisis por cohortes debe multiplicarse por el estudio de grupos diferentes, complicando la comprensión de la realidad. Pero es que la realidad es múltiple.

\section{Indicadores de feminización}

U tilizamos el concepto «procesos de feminización», en plural, porque expresa mejor las diversas estrategias de supervivencia en las trayectorias personales y generacionales de las mujeres. Los datos para analizar los procesos de feminización de las 63 universidades españolas en 1999 que proporciona el Instituto $\mathrm{N}$ acional de Estadística son numerosos. A partir de esos datos hemos creado 15 indicadores que sirven para identificar las dife rentes pautas de feminización en las universidades de nuestro país. Estos indicadores son los siguientes:

Porcentaje de mujeres entre estudiantes nuevos (M EN ). M ide el número de estudiantes que se matriculan de una carrera nueva, en primer curso. En la base de este indicador se incluye el primer ciclo y segundo ciclo, pero no doctorado. No tiene en cuenta la proporción de personas que se matricula en una segunda carrera. Con los últimos datos publicados por el Instituto N acional de Estadística para el curso 1998-1999, la media es 54 por 100, es decir, hay más mujeres que varones ingresando en la universidad. La diferencia extrema entre universidades es 2,6 veces, desde 74 por 100 de mujeres estudiantes nuevas en la Universidad de Vic, hasta el mínimo 24 por 100 en la Politécnica de Cataluña. Los dos extremos coinciden en la misma Comunidad Autónoma, Cataluña. Las universidades en que ingresan más mujeres son Vic, Valencia, Santiago, Complutense, D eusto, y Barcelona. Exceptuando la primera, son universidades grandes, clásicas, con bastantes facultades, y además están en ciudades grandes. El proceso de urbanización no es ajeno al de feminización de la Universidad.
Porcentaje de mujeres entre el total de estudiantes (M ES). Es sólo un poco menor al porcentaje de mujeres entre los estudiantes de primer curso, alcanzando 53 por 100. Este indicador tiene un comportamiento similar al anterior. Donde hay una mayor proporción de mujeres estudiando son Vic, Pompeu Fabra, Valencia, Santiago, Barcelona, D eusto, Complutense, Autónoma de Barcelona y Autónoma de M adrid. Las universidades con una proporción menor de estudiantes-mujeres son las tres politécnicas, U N ED , y cinco universidades privadas: Pontificia de Salamanca, Pontificia de Comillas, Alfonso X el Sabio, Antonio de Nebrija y Europea de M adrid.

Porcentaje de mujeres entre estudiantes de Escuelas Técnicas (M ET). Este indicador presenta la media más baja de toda España (25 por 100). Todas las universidades, públicas y privadas tienen porcentajes de mujeres en este tipo de carreras por debajo del 50 por 100. Las universidades de Santiago y $N$ avarra, ambas en el norte, son las únicas que superan el 40 por 100 . Algunas universidades tienen al rededor de un tercio de mujeres entres sus estudiantes en Escuelas Universitarias T écnicas. Estas universidades 0 bien están situadas en el norte de la península 0 en la Comunidad Valenciana: Burgos, Valladolid, M iguel Hernández, deElche y Jaumel, de Castellón.

Porcentaje de mujeres entre estudiantes de Escuelas Técnicas Superiores (M TS). Es 28 por 100, algo superior al porcentaje en Escuelas T écnicas, aproximadamente la mitad de la media. $\mathrm{H}$ ay pocas mujeres estudiando en ingenierías, pero también es cierto que esa proporción está incrementando a más velocidad que en otras carreras. Ese nuevo proceso ya es visible en carreras como Arquitectura. La distribución de mujeres en Escuelas Técnicas Superiores es bastante más azarosa en este indicador, igual que en el anterior, pues supone universidades que a veces sólo tienen una Escuela Técnica Superior, frente a otras que son verdaderas universidades politécnicas. Las tres universidades politécnicas marcan la pauta de esta distribución de mujeres, que varía entre 11 por 100 y 50 por 100, siendo la Universidad de las I slas Baleares la que tiene menos mujeres. La Universidad Católica de Ávila destaca con una proporción alta de mujeres (50 por 100). Pero la distribución es más explicable por variables sociales que por la estructura de las universidades.

Porcentaje de mujeres entre estudiantes de Escuelas U niversitarias (M EE). Es 68 por 100, es decir, la más alta de todos los tipos de estudios. $H$ ay escuelas universitarias fundamentalmente femeninas (como Enfermería) y otras con proporciones más equilibradas de varones/mujeres (como Empresariales). La mayoría de las diplomaturas son para mujeres, pues la mínima es 40 por 100 de mujeres, la máxima 87 por 100. Las universidades con más mujeres en diplomaturas son M ondragón, Autónoma de $M$ adrid y D eusto. La estructura regional del proceso de feminización es pues centro y norte. 
Porcentaje de mujeres entre estudiantes de Facultades (M EF). Es 59 por 100, es decir, un poco por encima de la media (que es 53 por 100). El proceso de feminización de la universidad española ha comenzado principalmente por las Escuelas U niversitarias, pero le siguen las Facultades. Las diferencias extremas son 75 por 100 en Vic y 29 por 100 en la Politécnica de M adrid. Cataluña aparece como la Comunidad Autónoma más avanzada en los procesos de feminización universitaria. La segunda universidad con más mujeres en Facultades es Jaume I, seguida de Pompeu Fabra y D eusto, 0 viedo, Jaume I de Castellón, Rovira i Virgili, Girona, Salamanca y Santiago.

Porcentaje de mujeres entre estudiantes que terminan la carrera (M EC). Es el 59 por 100, es decir, un porcentaje relativamente más alto que la proporción de mujeres que estudian la carrera. Este dato indica que la mujer termina la carrera más que el varón. Las universidades «más femeninas» son: Pablo de O lavide, Alfonso X el Sabio y O berta de Catalunya. Las «más masculinas» a la hora de terminar la carrera son Pontificia de Salamanca, Politécnica de C ataluña, M ondragón, Politécnica de M adrid y Politécnica de Valencia.

Porcentaje de mujeres entre estudiantes de doctorado (MED). Se refiere a estudiantes matriculados en los dos primeros años de estudios de doctorado. Las mujeres son 51 por 100. Pertenecen a cohortes mayores de edad, y por lo tanto son mujeres que parten de situaciones de desigualdad anteriores más acentuadas. La proporción entre los estudiantes de doctorado es la mitad y la dispersión es menor que en los casos anteriores: Las universidades con más doctorandas son Vic, Salamanca y Burgos, todas en el norte.

Porcentaje de mujeres entre las personas que obtienen el título de doctor (M D 0). La proporción es 42 por 100, lo que refleja un decremento con respecto al porcentaje de mujeres que se matriculan en estudios de doctorado. Eso sugiere que el proceso de terminar la tesis es en el que más mujeres abandonan. Son muchas las personas que no completan los estudios de doctorado, pero las que abandonan son más mujeres. Estos datos tienen que entenderse con precaución, puesto que no son las mismas cohortes. D ado que la situación ha cambiado recientemente no son situaciones equivalentes. En Politécnica de Cataluña hay sólo 19 por 100 de mujeres entre las personas que obtienen el título de doctor; en San Pablo son mujeres siete de cada diez de todas las personas que obtienen el doctorado (los datos de obtención del título de doctor se refieren a 1998). Terminar la tesis supone pues un proceso de discriminación, asociado a diferencias grandes por universidades. El máximo de doctoras (mujeres) se produceen las universidades de San Pablo La Rioja y D eusto. N inguna de estas universidades es central, lo que llama la atención. Q uizás por ser universidades menores, el apoyo a las mujeres es mayor y se alienta más a los estudiantes a continuar con los estudios.
Porcentaje de mujeres entre el profesorado (M PR). Se refiere al profesorado de todo tipo. Es la tercera parte (34 por 100). Es un indicador con capacidad de diferenciar, pues supone un nivel de desigualdad mayor por géneros. No tiene en cuenta los niveles de profesorado de esas mujeres, ni la precariedad de sus contratos. Globalmente es una variable que explica la no utilización de recursos humanos en al gunas universidades. Este indicador no presenta diferencias extremas entre universidades, al rededor de dos veces. Pero la discriminación es evidente y se observa en todas las universidades españolas: entre 42 por 100 de mujeres que terminan el doctorado, y 34 por 100 que consiguen un puesto de trabajo. Las universidades que tienen muchas mujeres estudiando son sobre todo públicas (o para-públicas como D eusto) y clásicas. En cambio las universidades con profesoras son sobre todo privadas, y varias de las públicas catalanas.

Porcentaje de mujeres entre el profesorado de EscuelasT écnicas U niversitarias (M PT). M ientras para estudiantes éste es el indicador con menos mujeres, en el caso de las profesoras, la situación está sensiblemente mejor en las Escuelas Técnicas U niversitarias, que en las Escuelas Técnicas Superiores. En Las Palmas y Murcia las mujeres sólo representan el 11 por 100 del profesorado. Dieciséis universidades de las treinta y dos universidades con Escuelas Técnicas tienen menos del 20 por 100 de mujeres entre el profesorado. Sólo Ramón Llull tiene más de un tercio de mujeres entre el profesorado (44 por 100) y dos universidades del norte, Valladolid, y León llegan al 30 por 100.

Porcentaje de mujeres entre el profesorado de Escuelas T écnicas Superiores (M PS). Es 18 por 100, es decir, cerca de la mitad de la media. Es la proporción menor de mujeres en cualquier colectivo universitario (profesorado o alumnado). Es el indicador que tiene más posibilidades de cambiar en el futuro; ya lo está haciendo, puesto que en realidad aumenta año tras año. No obstante, este indicador mantiene una dispersión considerable ( 5 veces) entre 9 por 100 en Rovira i Virgili y 45 por 100 en 0 viedo.

Porcentaje de mujeres entre el profesorado de Escuelas U niversitarias (M PE). Es 51 por 100, es decir, bastante superior a la media de mujeres docentes (que es 34 por 100). Las Escuelas Universitarias, con carreras cortas, presentan unos indicadores de feminización más altos que la media. Los centros con más estudiantes mujeres y con más profesoras son las Escuelas U niversitarias. Una razón es que se trata de un puesto peor pagado, sin dedicación a la investigación, más masificado, menos competitivo, para el que no se necesita doctorado. A menudo es un segundo empleo. Además, la dispersión entre universidades es bastante elevada, desde el mínimo de 33 por 100 en la Pontificia de Salamanca, al máximo 97 por 100 en Universidad de N avarra. Estas diferencias sugieren que las Escuelas U niversitarias están dedicadas a estudios tradicionalmente «para mujeres». 
Porcentaje de mujeres entre el profesorado de Facultades (M PF). Es 35 por 100, aproximadamente igual a la media (34 por 100). Las Facultades son mayoritariamente para estudiantes mujeres (59 por 100) pero con un profesorado de mujeres bastante más reducido en número. La dispersión de universidades varía entre la mínima de 20 por 100 de mujeres en las Facultades de la U niversidad Politécnica de C ataluña, y la máxima de 58 por 100 de mujeres en Alfonso X el Sabio, que es la universidad española con mayor proporción de profesoras en Facultades.

Porcentaje de mujeres catedráticas entre el total de catedráticos/as (M CA). Este indicador se refiere a las universidades públicas, ya que son las únicas que publican datos a través de instituciones oficiales. Incluye catedráticos de Escuela U niversitaria y de Universidad.7 Es el indicador con menos mujeres: 15 por 100. Las universidades con más catedráticas son por orden: Rovira i Virgili, Vigo, Pública de Navarra, Jaume I de Castellón, Universidad Autónoma de Barcelona, Pompeu Fabra y Valencia. El norte, y sobre todo C ataluña, alcanza las proporciones más altas. Las universidades más «masculinas» en cuanto a cátedras son: M iguel Hernández, Carlos III, Lleida, Universitat Politècnica de Catalunya, Alcalá de H enares y Cádiz. Son en general universidades con estudios más técnicos. La mayoría se encuentran en el centro y sur de España, aunque hay excepciones como la Universitat Politècnica de Catalunya.

\section{Procesos de feminización}

Se observan dos tipos distintos de desequilibrios por género en las universidades españolas. En la Tabla 1 se mide la dispersión de las variables fundamentales de forma resumida. Las dife rencias entre estas variables son constantes. Siguen una pauta de crecimiento sin saltos. H ay dos momentos, o procesos de selección más puntuales, en que la mujer está bastante más discriminada. Las diferencias aumentan en el indicador MD O, es decir, la proporción de mujeres que obtienen el título de doctor, en cuyo caso las diferencias entre universidades superan las 6 veces. Acceder al profesorado supone diferencias casi tres veces. Pero el segundo proceso en donde las universidades vuelven a diferenciarse mucho es en la proporción de mujeres numerarias, y sobre todo en llegar a ser catedráticas; ninguna universidad española tiene más de 25 por 100 de mujeres entre sus catedráticos. La estructura universitaria española es desigual de forma bastante constante; existe una estructura determinada, que no se comporta de forma azarosa. Los datos señalan también en qué procesos las universidades adoptan pautas más diferenciadas unas de otras. Es a la hora de conseguir el título de doctor (MDO), en la posibilidad de obtener la titularidad (MCT), y sobre todo la cá-
Tabla 1

Dispersión de las variables de feminización univers taria

\begin{tabular}{|ccccc|}
\hline Variable & Varía entre (\%) & $\begin{array}{c}\text { N úmero } \\
\text { de veces }\end{array}$ & $\begin{array}{c}\text { Desviación } \\
\text { típica }\end{array}$ & Varianza \\
\hline MEN & $24-74$ & 2,6 & 9 & 78 \\
MES & $25-69$ & 2,8 & 8 & 71 \\
MEC & $21-87$ & 4,1 & 12 & 153 \\
MED & $12-76$ & 6,3 & 10 & 94 \\
MDO & $19-71$ & 3,7 & 10 & 96 \\
MPR & $18-51$ & 2,8 & 6 & 36 \\
MCA & $4-26$ & 6,5 & 5 & 25 \\
\hline
\end{tabular}

Fuente: Tablas 3 y 4.

tedra (MCA) en donde las universidades mantienen modelos diferentes. Los datos dan una impresión de flujo o proceso, pero no se trata de una misma cohorte o generación, sino de un corte en el tiempo de las universidades españolas. Cada indicador se refiere a grupos distintos de varones y mujeres, a poblaciones distintas, que además van incrementando en edad desde que entran en la universidad (M EN), hasta aquéllas que obtienen la cátedra (MCA).

La Tabla 2 muestra el proceso de feminización de las universidades españolas al final del siglo xx. Son cohortes distintas, por lo que no es un análisis longitudinal8. La tabla presenta los procesos de cambio que experimenta la presencia de mujeres en la universidad, desde que se matriculan en el primer año de carrera en la universidad, hasta que llegan a ser catedráticas. Entre las personas que empiezan la universidad hay 54 por 100 de mujeres, pero en el total de estudiantes de universidad de todas las universidades, carreras, y años, el porcentaje de mujeres es un poco menor: 53 por 100. Este decremento tan mínimo sugiere que el proceso de feminización inicial está terminando, aunque aún no ha acabado. Las mujeres matriculándose por primera vez en la universidad son ya 54 por 100 , es decir, más numerosas que los varones. D ado que a esas edades la proporción de varones y mujeres en la población general es prácticamente igual, la universidad española parece ya «demasiado» feminizada, y es posible que esa tendencia pare, aunque es improbable que se invierta. Estos porcentajes, con más mujeres que varones en la universidad, son similares en otros países desarrollados. España está al nivel de países como Estados U nidos, Suecia, Dinamarca, N oruega, Canadá o Australia (U N ESC 0, 1999) en donde las mujeres han superado a los varones tanto en proporción de estudiantes como de egresados universitarios. 
Tabla 2

Evolución de proceso de feminización de las univerśdades españolas (año 1999)

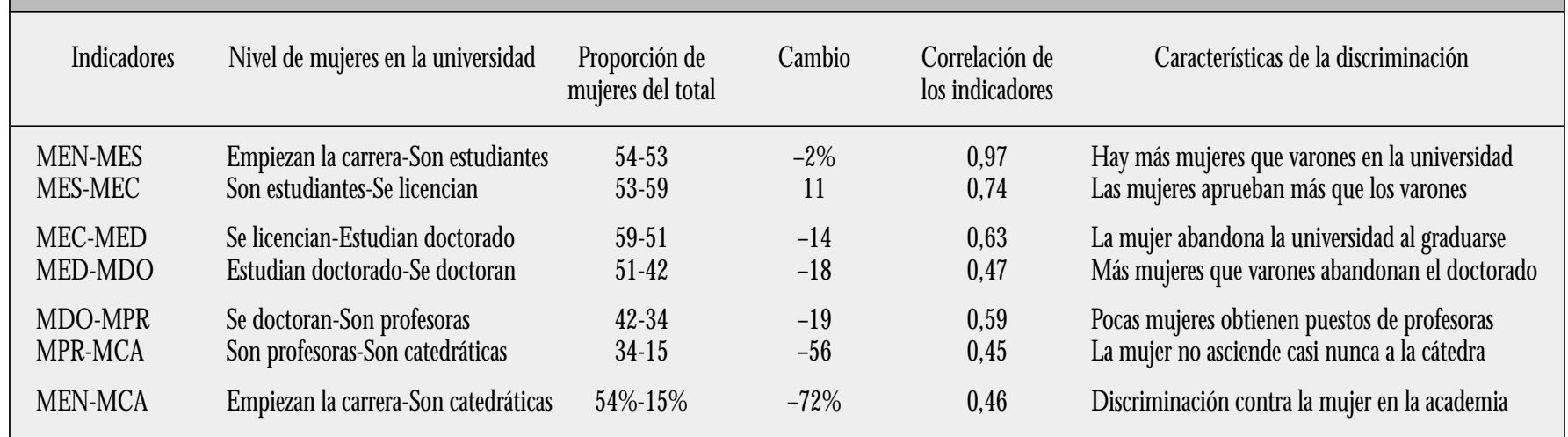

Fuente: Tablas 3 y 4 .

Se licencian relativamente más mujeres que las que estudian. En nuestro país, del total de estudiantes en la universidad 53 por 100 son mujeres, pero de las personas que terminan la carrera 59 por 100 son mujeres. Es el único proceso de feminización en que la mujer aumenta su participación. Una explicación de este aumento de la proporción de mujeres respecto a la de los hombres es que las mujeres abandonan los estudios en menor medida que los varones. El varón recupera su «estabilidad estadística» a la hora de estudiar el doctorado, donde la proporción para cada género es quasi-salomónica: del 51 por 100. La ventaja inicial de la mujer al terminar la carrera (son 59 por 100) desciende a la hora de decidir el doctorado hasta el 51 por 100. Los estudios de tercer ciclo presentan todavía un obstáculo para las mujeres, aunque muchas mujeres ya lo están superando. M ientras que la correlación entre M ES y M EC es 0.74 , la correlación de MEC y MED desciende a 0,63 y el descenso todavía es más pronunciado entre M ED y MD 0, 0,46. Esto se explica porque la distribución de mujeres que deciden realizar el doctorado puede variar - y lo hace- bastante más que el hecho de estudiar y terminar la carrera. La mayoría de los/as estudiantes españoles deciden abandonar la U niversidad cuando logran el título de diplomado, licenciado, o ingeniero. Sólo una minoría decide realizar el doctorado. En esa minoría los varones recuperan la superioridad que mantienen a partir de ese momento de forma creciente según avanzan en edad. Son muy pocas las mujeres, en proporción, que terminan y se convierten en doctoras.

Pero así como las mujeres terminan la carrera más que los varones, en el doctorado ocurre al revés. Con la precaución metodológica de que se refiere a cohortes distintas y no a procesos biográficos lineales, la mujer interrumpe el doctorado (no lo termina) en una proporción mucho mayor. La situación universitaria española en estudios de tercer ciclo presenta dos características negativas básicas: muy pocas personas realizan el doctorado (apenas el 4 por 100 de los/as estudiantes universitarios); además pocas de esas personas obtienen el título de «Doctor».En ese proceso de doble selección la presencia de mujeres desciende de 51 por 100 a 42 por 100. De todas las personas que abandonan la mayoría son mujeres. Por eso la correlación es bastante más baja, la menor de todos los procesos de feminización que se analizan aquí: 0,46. Realizar la tesis doctoral es un proceso largo, intrincado en España. En el ínterin abandonan casi un 20 por 100 más las mujeres que los varones. Este abandono es uno de los procesos que más deben cambiar en el siglo XXI si se pretende una igualación por géneros dentro de la Universidad. Convendría analizar las causas que explican que la mujer no acabe la tesis doctoral, fuera del tópico de que se casan, o de que tienen hijos/as en vez de escribir la tesis. ${ }^{9}$ Una explicación puede ser la falta de referentes femeninos entre el profesorado, que las animen a continuar ante las dificultades que supone realizar una tesis doctoral. El proceso de feminización comienza por los/as estudiantes de primero, y continúa en todo el recorrido académico hasta llegar a profesoras, y finalmente a catedráticas. En cada escalón de esta jerarquía las mujeres pasan de ser mayoría a no formar ni una cuarta parte del colectivo.

A partir del doctorado la discriminación de la mujer es cre ciente. Entre las personas que obtienen el título de doctor en España hay sólo 42 por 100 de mujeres; pero entre las personas que consiguen ser profesores de universidad - a cual quier nivel- baja a 34 por 100 de mujeres, es decir, un decremento re lativo del 25 por 100. La correlación es más baja que las anteriores: 0,59. El decremento en el número de mujeres que se observa en los porcentajes de mujeres que estudian el doctorado (51 por $100)$, que se doctoran (42 por 100) continúa a la hora de conseguir un puesto de trabajo académico, pues sólo hay 34 por 100 de mujeres profesoras. Q ue las universidades españolas no tengan profesoras porque son del género femenino es una discrimi- 
nación a superar. No puede argumentarse que el pool o cantera es reducida, pues el porcentaje de mujeres que potencialmente pueden ser profesoras supera al de varones. Las mujeres matriculadas en estudios de doctorado superan ligeramente a los varones, lo que puede ser interpretado como que las mujeres tienen la intención de seguir una carrera académica.

El estudio realizado por M arisa GARCíA DE CORTÁZAR y M aría Antonia GARCíA DE LEÓN titulado M ujeres en minoría: U na investigación sociológica sobre las catedráticas de universidad en Es paña (1997) se preocupa por la escasa presencia de mujeres entre los catedráticos. Las autoras parten de la idea de que «las élites profesionales femeninas son outsiders dentro del propio campo profesional en el que ejercen, siendo los ámbitos que concentran mucho poder (ya sea poder político, poder económico, poder académico... ) donde el modelo cultural masculino se muestra prácticamente sin erosionar» (p. 9). La proporción de mujeres profesoras en 1987 es 28 por 100. En toda una década de progreso, este porcentaje sólo aumenta a 33 por 100 en 1997. El progreso realizado en el proceso de feminización de la universidad española es pequeño. G arcía y García señalan que ese proceso es más difícil cuanto más se acerca a la «cúpula académica», es decir, a la cátedra. El estudio entrevista a 254 de las 555 catedráticas de universidad en ese momento en la universidad española10. A puntan que «las mujeres catedráticas son una minoría simbólica dentro de un grupo profesional masculino que desarrolla sus tareas en una institución que, paradójicamente, cuenta con una mayoría femenina», se refieren a las mujeres estudiantes (GARcía y García, 1997: 28)11. Aunque los datos ofrecidos no son contrastados con una muestra de catedráticos-varones, las hipótesis que sugieren son diversas. Las mujeres catedráticas tardan siete años de media en pasar de titular a catedrática, pero 70 por 100 lo logran a la primera (《oposición» 0 «concurso»). M ás de un tercio provienen de familias en que el padre es ya universitario (34 por 100). Esta proporción es mucho menor en el caso de la madre (9 por 100), aunque también es elevada para el contexto español. Las autoras demuestran con sus datos que «de las mujeres catedráticas que se han casado, el 40 por 100 lo ha hecho con catedráticos, un hecho que sin duda ha tenido que influir en sus pautas profesionales» (G ARCía y García, 1997: 60). Se refieren a que actualmente su esposo es catedrático, no a que cuando se casaron su esposo ya lo era.

En el estudio cualitativo de este mismo libro señalan que la pareja varón-profesor casado con estudiante-mujer es bastante usual. El estudio menciona también «una especial relación con el padre» (p. 66). Esta afirmación apoya la idea de la necesidad de tener un referente; alguien que afecte emocional y personalmente a la persona. Las autoras comentan la importancia del padre, pero también puede ser al guna persona académica. En cualquier caso, 40 por 100 de mujeres catedráticas casadas con catedrático es un porcentaje significativamente alto. Entre catedráticas hay además un porcentaje elevado de solteras: 27 por 100. Sin tener en cuenta el estado civil - que cada vez es más irrelevante para la fecundidad-37 por 100 de catedráticas no tienen hijos/as. Teniendo en cuenta que todas son mayores de 30 años (y de 30 a 39 años son sólo el 6 por 100 siendo la moda entre 40 y 49 años que son el 61 por 100) esa proporción de catedráticas sin hijos/as (37 por 100) es alta. El retrato-robot de la mujer catedrática en España es pues: mujer soltera, si está casada no tiene hijos/as, y una proporción elevada está casada con un varón que actualmente es catedrático. Es una visión peculiar de un grupo femenino con relativo poder dentro de la universidad española, a pesar de su escaso número (o precisamente por ello). La conclusión del estudio es que «los porcentajes de catedráticas son anómalos y reflejan los círculos androcéntricos del poder académico (el efecto old boys club, la cooptación casi siempre inconsciente por parte de los hombres [varones] de candidatos varones, 'sus iguales'). Por tanto, como defienden estas autoras, el mero transcurso del tiempo, sin medidas ad hoc, sin medidas que quieran erosionar el androcentrismo del poder académico, no cambiará la situación» en España (GARCía y García, 1997: 75).

Se tiene así una idea global de los diversos procesos de discriminación. Abarca desde que la mujer se matricula por primera vez en la universidad (M EN) hasta que llega a ser catedrática de universidad (M CA)12. Estos indicadores en los extremos del proceso van desde 54 por 100 hasta 15 por 100 de mujeres respectivamente. A lo largo de la carrera universitaria la mujer experimenta una reducción en porcentaje del 74 por 100. La correlación de estos indicadores extremos es positiva (afortunadamente) de 0,46, sugiriendo que los procesos de feminización de las diversas universidades no son azarosos. Siguiendo con la polé mica iniciada por G ARCía y G ARcía (1997), que haya muchas mujeres en la universidad como estudiantes no significa que vaya a haber muchas como catedráticas. Las universidades que nombran catedráticas a mujeres tienen poco que ver con las universidades que las admiten como estudiantes, pues son procesos distintos. $\mathrm{H}$ ay universidades democráticas en cuanto a admitir mujeres como estudiantes, pero masculinas en cuanto a contratarlas como profesoras o catedráticas, como la Universidad Carlos III. Es un proceso heterogéneo, con pautas distintas para cada universidad. El cambio universitario ya no depende de tener más mujeres estudiantes, sino de la distribución de las mismas a través de las diferentes carreras. Es preciso, pues, estudiar las diferencias por universidades específicas, para descubrir nuevos procesos de discriminación en el sistema universitario español.

La Tabla 3 presenta los quince indicadores del proceso de feminización para las universidades españolas que ayuda a entender las pautas de conducta de universidades concretas. $H$ ay universidades tradicional mente de varones, como las tres politécnicas, y las dos pontificias. Tanto en la proporción de estudiantes, como en la de profesores, estas universidades son eminentemente mas- 


\section{Tabla 3}

Índices deféminización delas universidades españolas (1999)

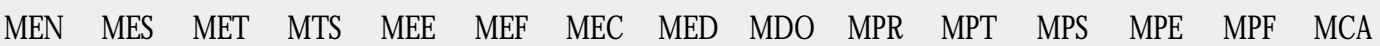

$\begin{array}{llllllllllllllll}\text { Universidades públicas } & 54 & 53 & 25 & 29 & 68 & 59 & 59 & 51 & 42 & 33 & 20 & 18 & 50 & 35 & 14,9\end{array}$

Alcalá de H enares

Alicante

Almería

Autónoma de Barcelona

Autónoma de Madrid

Barcelona

Burgos

Cádiz

Cantabria

CarlosIII

Castilla-La M ancha

Complutense de M adrid

Córdoba

LaCoruña

Extremadura

Girona

Granada

Huelva

Islas Baleares

Jaén

Jaumel de Castellón

La Laguna

LaRioja

León

Lleida

Málaga

Miguel Hernández de Elche

Murcia

0 viedo

Pablo de O lavide

País Vasco

Las Palmas

Politécnica de Cataluña

Politécnica de Madrid

Politécnica de Valencia

Pompeu Fabra

Pública de N avarra

Rey Juan Carlos

Rovira i Virgili

Salamanca

Santiago

Sevilla

U.N.E.D.

Valencia (Est. General)

Valladolid

Vigo

Zaragoza
$54 \quad 55$

$58 \quad 53$

$57 \quad 57$

6361

$62-62$

$55 \quad 53$

$56 \quad 52$

$50 \quad 49$

49

$55 \quad 54$

$\begin{array}{lll}63 & 61 & 26\end{array}$

$\begin{array}{lll}56 & 52 & 15\end{array}$

$55 \quad 51$

$57 \quad 54$

$57 \quad 56$

$\begin{array}{lll}58 & 57 & 25\end{array}$

$54 \quad 52$

$56 \quad 58$

$53 \quad 51$

$55 \quad 56$

$59 \quad 57$

$51 \quad 52$

$60 \quad 58$

$\begin{array}{lll}57 & 56 & 31\end{array}$

$21 \quad 20$

76

$\begin{array}{lll}59 & 62 & 53\end{array}$

$57 \quad 59 \quad 48$

$\begin{array}{lll}61 & 67 & 54\end{array}$

$67 \quad 56$

$\begin{array}{lll}58 & 65 & 51\end{array}$

$\begin{array}{lll}N / A & 34 & 68\end{array}$

$\begin{array}{llll}33 & 32 & 70 & 61\end{array}$

$\begin{array}{llll}15 & 26 & 67 & 58\end{array}$

$65 \quad 55$

$62 \quad 63$

$\begin{array}{ll}56 & 51\end{array}$

$54 \quad 50$

$23 \quad 25$

$63 \quad 59$

$57 \quad 5$

41

$41 \quad 35$

$\begin{array}{llll}12 & N / A & 49 & 37\end{array}$

8,7

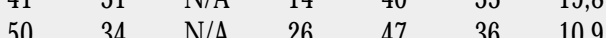

$\begin{array}{lllllll}40 & 37 & 18 & N / A & 57 & 34 & 21,0\end{array}$

$\begin{array}{lllllll}48 & 36 & N / A & 16 & 56 & 32 & 11,8\end{array}$

$\begin{array}{lllllll}49 & 41 & \mathrm{~N} / \mathrm{A} & \mathrm{N} / \mathrm{A} & 63 & 37 & 19,5\end{array}$

$\begin{array}{lllllll}50 & 34 & 17 & \mathrm{~N} / \mathrm{A} & 55 & 41 & 13,2\end{array}$

$\begin{array}{lllllll}29 & 34 & 13 & 14 & 53 & 30 & 9,0\end{array}$

$\begin{array}{llllll}26 & 15 & 17 & 54 & 23 & 12,5\end{array}$

$\begin{array}{lll}27 & 72 & 58\end{array}$

$62 \quad 53 \quad 37$

$\begin{array}{lllllll}37 & 33 & 18 & 21 & 49 & 33 & 16,2\end{array}$

$\begin{array}{lllllllllll}67 & 60 & 60 & 57 & 49 & 37 & \text { N/A } & 31 & 54 & 36 & 14,9\end{array}$

$66 \quad 57$

$\begin{array}{llll}57 & 58 & 43 & 37\end{array}$

$\begin{array}{llllll}29 & 16 & 21 & 36 & 30 & 13,2\end{array}$

$28-24-70$

58

$53 \quad 47$

34

$32 \quad 15$

$15 \quad 13$

$\begin{array}{lll}58 & 34 & 16,2\end{array}$

$\begin{array}{llll}28 & 14 & 72 & 63\end{array}$

$63 \quad 58 \quad 47$

35

$52 \quad 52$

20

$\begin{array}{ll}29 & 65\end{array}$

59

$61 \quad 49$

38

$\begin{array}{llllll}34 & \mathrm{~N} / \mathrm{A} & 15 & 52 & 39 & 17,5\end{array}$

$\begin{array}{llll}14 & 11 & 64 & 59\end{array}$

69

$64 \quad 50$

$64 \quad 46$

36

32

$\begin{array}{llllll}32 & 16 & 10 & 42 & 33 & 14,3\end{array}$

19

$36 \quad 65$

61

$64 \quad 51$

41

$34 \quad \mathrm{~N} / \mathrm{A} \quad \mathrm{N} / \mathrm{A} \quad 51 \quad 32 \quad 198$

$41 \quad 44$

$55 \quad 55$

$56 \quad 56$

$32 \quad 27$

$\begin{array}{lll}27 & 64 \quad 66\end{array}$

$61 \quad 54$

45

$\begin{array}{llllll}30 & 16 & 15 & 46 & 38 & 10,2\end{array}$

27

$\begin{array}{lll}30 & 65 & 61\end{array}$

$63 \quad 51$

$35 \quad$ N/A

N/A 25

$\begin{array}{lll}\mathrm{N} / \mathrm{A} & 42 & 22,7\end{array}$

$\begin{array}{llll}32 & 30 & 67 & 62\end{array}$

$60 \quad 48$

67

$\begin{array}{llllll}39 & 22 & 25 & 65 & 37 & 15,5\end{array}$

$\begin{array}{llllll}36 & \mathrm{~N} / \mathrm{A} & 30 & 53 & 38 & 15,4\end{array}$

$\begin{array}{lll}30 & 67 & 62 \\ 36 & 70 & 60\end{array}$

$\begin{array}{lll}63 & 54 & 47\end{array}$

$\begin{array}{llll}14 & 20 & 68 & 60\end{array}$

$\begin{array}{llll}16 & 22 & 62 & 60\end{array}$

$\begin{array}{llll}28 & 26 & 65 & 65\end{array}$

$64 \quad 54$

34

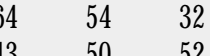

32

32

31

12

$45 \quad 35$

16,5

$\begin{array}{llllll}61 & 63 & \mathrm{~N} / \mathrm{A} & \mathrm{N} / \mathrm{A} & 71 & 52\end{array}$

$60-49$

31

$\begin{array}{lllll}15 & 15 & 40 & 35 & 18,1\end{array}$

$\begin{array}{lllll}11 & 9 & 39 & 32 & 13,4\end{array}$

$\begin{array}{llllll}56 & 55 & 20 & 31 & 68 & 62\end{array}$

$\begin{array}{llllll}53 & 51 & 26 & 29 & 70 & 59\end{array}$

$87 \quad 44 \quad \mathrm{~N} / \mathrm{A}$

$\begin{array}{llllll}35 & 18 & 34 & 46 & 35 & 15,9\end{array}$

$\begin{array}{llllll}24 & 25 & 23 & 25 & 56 & 50\end{array}$

$60 \quad 53$

45

$\begin{array}{llllll}35 & 23 & 20 & 56 & 33 & 18,2\end{array}$

$\begin{array}{llllll}30 & 31 & 29 & 32 & \mathrm{~N} / \mathrm{A} & 29\end{array}$

$\begin{array}{lll}55 & 47 & 42\end{array}$

34

$29 \quad 32$

$32 \quad 29$

24

$18-20$

19

115

14

$\begin{array}{lll}57 & 39 & 18,2\end{array}$

$35 \quad 35$

27

$\begin{array}{llllll}59 & 62 & 37 & \mathrm{~N} / \mathrm{A} & 60 & 65\end{array}$

$65 \quad 63$

30

$21 \quad 20$

$\begin{array}{lllll}55 & 52 & 29 & 33 & 71\end{array}$

$\begin{array}{llllll}55 & 52 & 21 & 73 & 61 & 46\end{array}$

$\begin{array}{llllll}57 & 59 & 21 & 29 & 71 & 65 \\ 60 & 59 & 27 & 39 & 70 & 64\end{array}$

$\begin{array}{llll}59 & 56 & 53 & 48\end{array}$

40

$\begin{array}{lll}5 / A & N / A & N / A\end{array}$

64

$\begin{array}{llllll}64 & 64 & 45 & 45 & 71 & 65\end{array}$

$64 \quad 58 \quad 50$

50

$\begin{array}{llllll}33 & N / A & 21 & 34 & 33 & 20,6\end{array}$

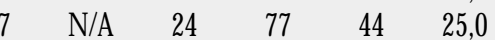

$\begin{array}{llllll}46 & 22 & \mathrm{~N} / \mathrm{A} & \mathrm{N} / \mathrm{A} & 50 & \mathrm{~N} / \mathrm{A}\end{array}$

$\begin{array}{llllll}33 & \mathrm{~N} / \mathrm{A} & 10 & 62 & 33 & 26,1\end{array}$

$\begin{array}{llllll}53 & 53 & 26 & 26 & 64 & 6\end{array}$

$\begin{array}{llllll}45 & 46 & 16 & 14 & \text { N/A } & 50\end{array}$

$\begin{array}{lll}65 & 67 & 52\end{array}$

45

$\begin{array}{lllll}33 & \text { N/A } & 53 & 36 & 13,1\end{array}$

$\begin{array}{llllll}65 & 64 & 14 & 27 & 69 & 64\end{array}$

$\begin{array}{lll}60 & 48 & 50\end{array}$

$\begin{array}{llllll}36 & \mathrm{~N} / \mathrm{A} & 15 & 59 & 35 & 13,5\end{array}$

$\begin{array}{llllll}56 & 53 & 33 & 33 & 69 & 58\end{array}$

$58 \quad 53$

$55 \quad 53$

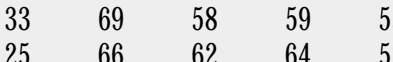

$26 \quad 70 \quad 60$
$59 \quad 53$ $\begin{array}{rrrrrrr}50 & 30 & 23 & 13 & 41 & 32 & 10,5\end{array}$

$\begin{array}{lllllll}41 & 35 & \mathrm{~N} / \mathrm{A} & \mathrm{N} / \mathrm{A} & 44 & 32 & 20,0\end{array}$

$\begin{array}{lllllll}46 & 36 & 30 & 22 & 51 & 36 & 17,7\end{array}$

$\begin{array}{lllllll}40 & 34 & 26 & 14 & 42 & 41 & 25,5\end{array}$ 
Tabla 3 (cont)

indices de feminizadión de las universidades esoañolas (1999)

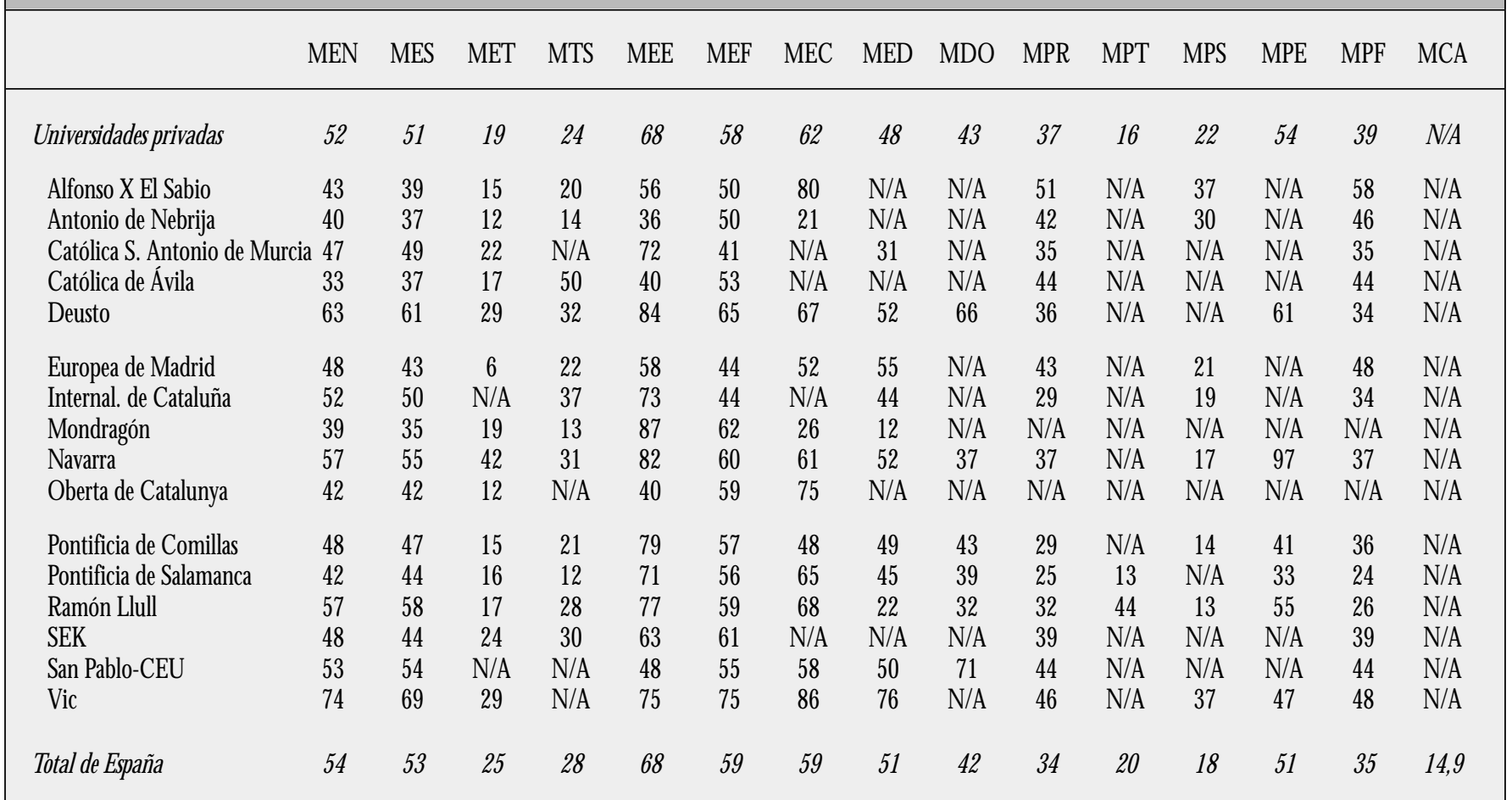

Nota: Los datos referentes a catedráticos sólo se publican para universidades públicas.

culinas. La universidad más masculina de España es la Politécnica de Cataluña, que mantiene porcentajes muy bajos de mujeres, sobre todo si se compara con la Universitat de Barcelona - también pública y en Barcelona- que tiene 62 por 100 de estudiantes y 41 por 100 de profesoras. En Universidad Politécnica de Cataluña hay una mujer por cada cuatro estudiantes varones ( 25 por 100), y aproximadamente una mujer por cada seis profesores (18 por 100). En Universidad Politécnica de M adrid hay 31 por 100 de estudiantas y 19 por 100 de profesoras. Estas universidades están aún lejos del total de España que presenta un 53 por 100 de mujeres estudiantes y 34 por 100 de mujeres profesoras.

Los obstáculos se presentan a varios niveles: entrada en la universidad, realización del doctorado, y admisión en el profesorado de alguna universidad. La efectividad se mide al terminar la carrera, terminar la tesis doctoral, y llegar a catedrática. Son tres procesos distintos, que seguramente requieren políticas diferentes. La entrada a la Universidad, y sobre todo la terminación de los estudios (predoctorales), ya no es discriminante para la mujer en España: ingresan en la carrera 54 por 100 mujeres, son estudiantes 53 por 100, y terminan la carrera 59 por 100 mujeres. El número máximo de mujeres en la carrera está en universidades grandes, urbanas, públicas, y con estudios de licenciatura (facultades), la mayoría de ellas localizadas en el norte del pais: Vic,
Valencia, Santiago, Pablo de Olavide, Barcelona y Pompeu Fabra. M ientras que las universidades que más se «especializan en varones» son las privadas. Eso sugiere la existencia de una discriminación en la sociedad española: las familias pagan los estudios de los hijos, pero envían a las universidades públicas a sus hijas. Parece una afirmación extrema, pero es consistente con los indicadores analizados. La excepción son los estudiantes de ingeniería que todavía hoy acuden a las universidades públicas. Sólo las universidades públicas se permiten una inversión tan grande como la que necesitan las universidades politécnicas.

Las universidades privadas ingresan menos mujeres que la media, caracterizándose por ser instituciones sobre todo para varones. Las universidades privadas más clásicas como D eusto 0 N avarra son una excepción. Son universidades que en cierta me dida se comportan como las públicas. La U niversidad de N avarra, privada, admite a más mujeres (57 por 100) que es su homónima pública - Universidad Pública de Navarra- que admite a 55 por 100. La Universidad de N avarra mantiene sus indicadores de mujeres bastante altos: empiezan 57 por 100, estudian 55 por 100, y de todos los estudiantes que terminan la carrera 61 por 100 son mujeres. M ientras que los resultados son más magros en la Universidad Pública de N avarra: empiezan 55 por 100, estudian 52 por 100, y terminan la carrera 56 por 100. 
Sin embargo, la tendencia es la contraria en el doctorado: en la Pública de Navarra hay 48 por 100 de doctoras, mientras que en la privada de N avarra hay apenas 37 por 100 . H ay pues pautas diferentes de feminización, y no puede hablarse - en singularde un único proceso. La hipótesis de que las universidades feministas son las clásicas y grandes (con excepciones como Pompeu y D eusto), y las universidades masculinas son las politécnicas, pontificias, a distancia, y privadas (sin excepciones, pues C antabria tiene estudios politécnicos) queda bastante clara con los datos del indicador M ES. Las diferencias se evidencian en el tipo de centros. Respecto al número de estudiantes, los centros con más mujeres estudiantes son las Escuelas, con 68 por 100, le siguen las Facultades con 59 por 100 de mujeres estudiantes. Las Escuelas Técnicas Superiores con 28 por 100. Las Escuelas T écnicas con 25 por 100 presentan unos porcentajes que disminuyen a la mitad de mujeres estudiantes.

En cuanto al profesorado, los centros con más mujeres son de nuevo las Escuelas Universitarias, donde el profesorado tiene sueldos inferiores, se realiza menos investigación, y no se realizan estudios de doctorado. Alcanzan a tener un 51 por 100 de mujeres entre el profesorado. Son los únicos centros que tienen más de la mitad del profesorado formado por mujeres. D espués están las Facultades con 35 por 100; por último el porcentaje más bajo de mujeres profesoras aparece en las Escuelas T écnicas y las Escuelas T écnicas Superiores (con 20 por 100 y 18 por 100 respectivamente). Las diferencias de datos por universidades varían de bido a la composición - a veces minoritaria - de estos tres tipos de centros. Las dos universidades en Navarra, por ejemplo, tie nen muchas mujeres estudiantes en Escuelas U niversitarias, así como H uelva o La Laguna, porque se refieren a Escuelas de Enfermería y de Formación del profesorado. En Facultades, la universidad másfemenina es Alfonso X el Sabio. En EscuelasT écnicas Superiores las universidades con más mujeres son: Vic, Alfonso X, 0 viedo, M iguel Hernández y Complutense de $M$ adrid, las universidades privadas son también bastante masculinas en sus Escuelas Técnicas Superiores. D eusto se perfila como una universidad privada pero con características de universidad pública: poco profesorado, alumnado femenino, masificación. Eso proviene de que durante casi un siglo (1886 a 1968) fue la única universidad en el País Vasco, y por lo tanto asumió algunas pautas de universidad pública. Con el desarrollo de la Universidad del País Vasco, pública, es posible que D eusto cambie bastante en su estructura y organización.

Las universidades en que se gradúan (diploman, licencian, u obtienen el título de ingeniera/arquitecta) más mujeres son: Pablo de 0 lavide, Vic, Alfonso X, Universitat $O$ berta de $C$ atalunya, Ramon Llull, Rovira i Virgili y Universidad Autónoma de Barcelona. La Universidad Pompeu Fabra tiene muchas estudiantes, pero suspenden más que los varones. Universidades grandes como Complutense de M adrid, Barcelona o Valencia hacen lo mismo: tienen muchas mujeres estudiando, pero suspenden más a nivel relativo (si se comparan todas las universidades españolas en su conjunto). Las universidades que ingresan pocas mujeres las conservan hasta el final de la carrera; sobre todo las politécnicas, más aún que las pontificias.

El doctorado es otro proceso en donde la discriminación contra la mujer es evidente. De las personas que empiezan el doctorado 51 por 100 son mujeres, y de las que lo terminan 42 por 100. Es una tendencia que oculta otros procesos intermedios de discriminación, pues la correlación entre ambos indicadores es baja. Las universidades en donde hay más mujeres estudiando el doctorado no son las mismas en que terminan más el doctorado. Las universidades en que más mujeres realizan el doctorado son: Vic, Burgos, Salamanca, Rovira i Virgili, Complutense, y Universidad Autónoma de Barcelona. Son universidades con programas de doctorado de Letras y H umanidades en mayor proporción. Las universidades en que más mujeres terminan el doctorado son distintas entre sí: varias privadas como San Pablo y D eusto. Las demás son públicas: La Rioja, Lleida, M iguel H ernández de Elche, Zaragoza, Almería y Barcelona. Las universidades con pocas mujeres estudiando doctorado son las que a su vez tienen poco alumnado femenino, como era de esperar: politécnicas y pontificias.

En la «carrera» universitaria (para utilizar terminología goffmaniana) convertirse en profesora supone superar otro tipo de proceso de discriminación tanto formal como informal contra la mujer, paralelo pero no idéntico a la carrera universitaria o al doctorado. Es un proceso que a veces se solapa con el de doctorado, pues muchas de las personas que obtienen el doctorado en una universidad son profesores/as en la misma universidad o lo van a ser de inmediato. El nivel de endogamia de la universidad española es tan alto a veces que se producen situaciones ambiguas: hay bastantes personas que son al mismo tiempo alumna y profesora en la misma universidad. Las universidades con mujeres estudiantes son las clásicas y grandes; las que tienen muchas profesoras son las privadas. El modelo de universidad privada nueva (excluyendo D eusto y $\mathrm{N}$ avarra) es el de universidades-de-profesoras enseñando a estudiantes-varones. Las que tienen más profesoras de toda España son: Alfonso X, Rey Juan C arlos, Vic, Católica de Ávila, San Pablo, UNED, Europea de Madrid y Antonio de N ebrija. Casi todas son universidades jóvenes. Las únicas universidades que coinciden en tener muchas alumnas y muchas profesoras son Vic y la Universidad de Barcelona.

La lista de universidades de profesoras es distinta, por lo que se debe hablar de dos procesos de feminización diferentes. Entre las universidades con menos profesoras están las politécnicas y las pontificias. El resto de universidades con profesorado masculino son universidades con un contenido politécnico mayor, o bien son «periféricas»: Pontificia de Salamanca, M iguel H ernández de Elche, Córdoba, Pontificia de Comillas. El profesorado 


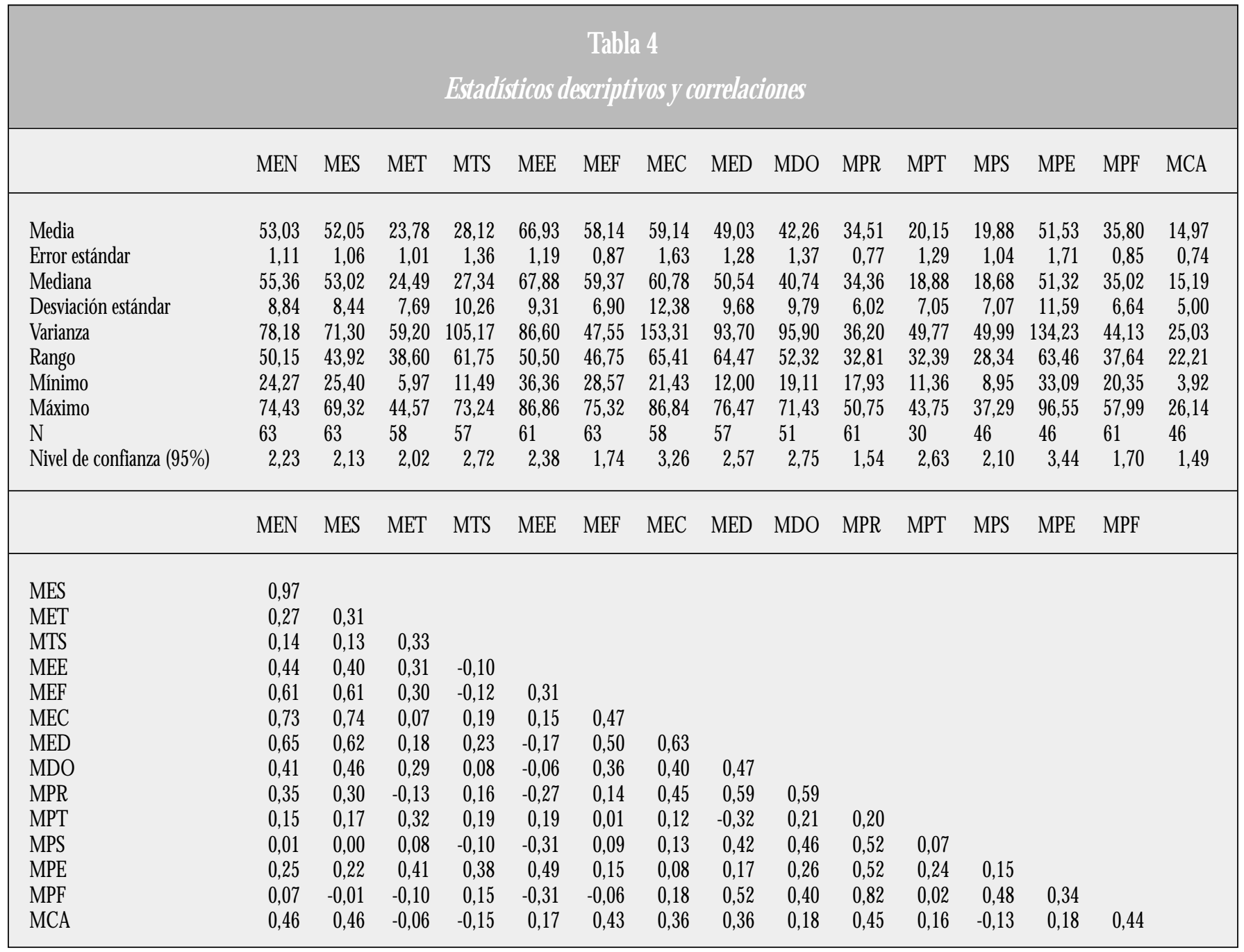

Fuente: Tabla 3.

femenino se concentra en las carreras cortas (diplomaturas), y el masculino en las Escuelas Técnicas superiores. En Facultades las tasas más altas de mujeres están en las universidades privadas: Alfonso X, Rey Juan C arlos, Vic y Europea de M adrid. En Escuelas T écnicas Superiores el máximo de profesorado femenino está en 0 viedo, pero seguido inmediatamente de las privadas Nebrija y Europea. Aunque las universidades privadas van cambiando según el tipo de centros, el profesorado femenino es dominante salvo en las pontificias. Las pautas de las privadas y de las públicas son diferentes. El cambio en el tipo de alumnado y de profesorado viene sobre todo de las privadas que rompen los moldes típicos de género en cuanto a carreras que seguir. 0 tra explicación es que el profesorado femenino es más barato, y con dedicación alta a la docencia (aunque no necesariamente a la investigación). El modelo de universidad privada es más estilo enseñanza primaria: profesoras enseñando a varones.

El proceso de privatización del sistema universitario, cada vez más evidente, puede producir un efecto en el proceso de femini- zación global de la Universidad española. Las universidades privadas tienden a matricular más varones, pero contratar más profesorado femenino. A igualdad de clase social los varones van a estudiar más a universidades privadas, y las mujeres a públicas. El modelo privado es de profesorado femenino, pero con un control masculino en la cúpula.

La Tabla 4 incluye las correlaciones relativas a los procesos de feminización analizados. También proporciona los intervalos mínimos y máximos de cada indicador. Los procesos de feminización son consistentes, es decir, las catorce variables están ordenadas de forma cronológica (según la carrera universitaria) y estructural (por tipos de centros). Las correlaciones entre las variables son altas al inicio del itinerario, entre M EN y M ES la correlación es 0,97 . M ás adelante en este itinerario la correlación es algo menor, M ES y M EC correlacionan 0,74. Baja significativamente en $M E C$ con M ED a 0,63, aunque todavía se mantiene bastante significativa. La significación es incluso menor entre M ED y M D 0, 0,47; aunque es importante señalar que conti- 


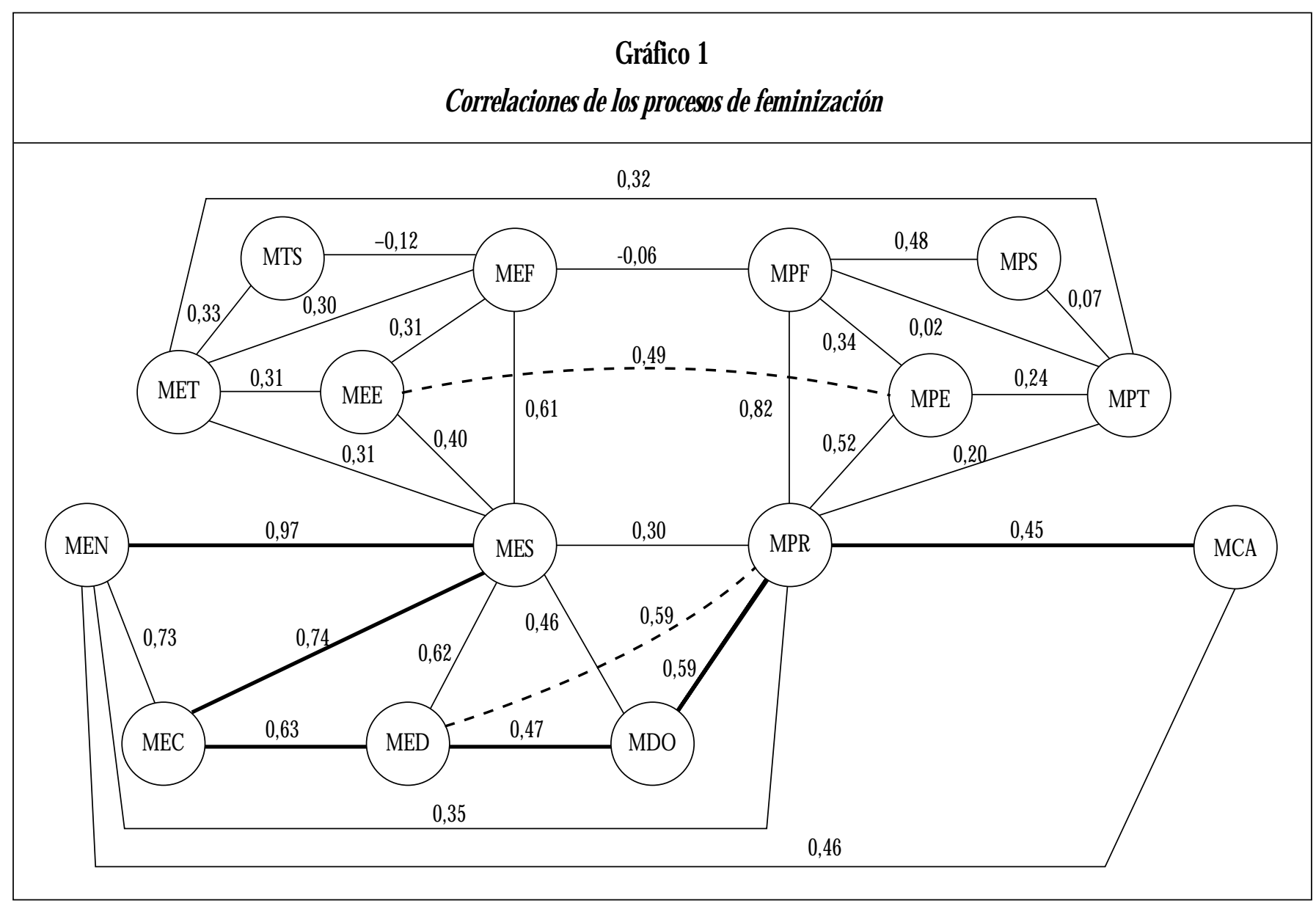

Fuente: Tabla 4.

núa siendo positiva. M D 0 y M PR tienen una correlación bastante alta $(0,59)$. La correlación final del itinerario entre M PR y MCA es 0,45. Todos los coeficientes son positivos y relativamente altos, aunque su nivel va bajando. Una explicación para entender la disminución de los niveles de correlación a medida que se sigue el itinerario es que el proceso de feminización de la universidad española es un fenómeno bastante reciente y que todavía no ha alcanzado los niveles superiores y de más edad. Se trata de cohortes de mujeres diferentes.

El Gráfico 1 muestra las correlaciones para los catorce indicadores aquí analizados para todas las universidades (públicas y privadas). Se marca de forma especial el itinerario que aquí se considera principal para entender el proceso de feminización: MEN, M ES, M EC, M ED, M D O, M PR, M CA. La correlación entre los extremos es positiva, 0,46 . $H$ ay una cierta relación entre universidades para mujeres, y universidades enseñadas por mujeres. La hipótesis es que la relación inversa es más frecuente: hay relación estrecha entre universidades de varones (profesores) y para varones (estudiantes). Este es el caso de las universidades politécnicas y las pontificias. Las estructuras de feminización son coherentes, y parece que se mantienen en el tiempo, aunque este estudio es de un corte de tiempo referente sólo al año 1999, último disponible con datos oficiales.

La existencia de universidades de-mujeres para-mujeres no se mantiene en las correlaciones por centros, pues son negativas. En M T S con M PS cuantas más estudiantas hay en Escuelas Técnicas Superiores, menos profesoras tienen esas Escuelas Superiores $(-0,10)$. La correlación negativa indica que todavía son dos procesos distintos, que las profesoras que hay hoy en día todavía no se contratan al mismo ritmo que se aceptan a las estudiantes. Algo similar puede verse en Facultades (MEF con MPF es $-0,06)$. Sin embargo, en el caso de las Escuelas Universitarias la relación (MEE con M PE) es positiva y sorprendentemente alta: 0,49 . $\mathrm{H}$ ay universidades que tienen Escuelas Universitarias que están marcadas por la adscripción a un género determinado (como Enfermería o M agisterio); en éstas, además, su profesorado es femenino. Algo similar ocurre en las Escuelas T écnicas. La correlación entre su alumnado y profesorado es 0,32.

En el itinerario cronológico central que va desde M EN hasta MCA, pasando por M PR, hay una relación alta destacable, que es la correlación 0,59 entre M ED mujeres realizando el doctora- 


\begin{tabular}{|c|c|c|c|c|c|c|c|c|c|c|c|c|c|c|c|}
\hline & & rdenar & jón de & as uni & versida & Talo & in losi & ndicac & ores de & Eemini & ración & & & & \\
\hline Universidades & MEN & MES & MET & MTS & MEE & MEF & MEC & MED & MDO & MPR & M PT & MPS & MPE & MPF & MCA \\
\hline Alcalá de H enares & 39 & 25 & 37 & 47 & 7 & 38 & 26 & 19 & 24 & 29 & 28 & $N / A$ & 27 & 22 & 41 \\
\hline Alicante & 15 & 31 & 34 & 39 & 38 & 46 & 38 & 40 & 25 & 49 & $\mathrm{~N} / \mathrm{A}$ & 39 & 41 & 40 & 20 \\
\hline Almería & 18 & 17 & 23 & 41 & 45 & 19 & 11 & 11 & 7 & 31 & $\mathrm{~N} / \mathrm{A}$ & 8 & 29 & 25 & 36 \\
\hline Autónoma de Barcelona & 5 & 8 & 46 & 50 & 10 & 8 & 7 & 6 & 29 & 14 & 17 & $\mathrm{~N} / \mathrm{A}$ & 12 & 35 & 5 \\
\hline Autónoma de M adrid & 8 & 10 & $\mathrm{~N} / \mathrm{A}$ & 45 & 4 & 41 & 12 & 29 & 14 & 22 & $\mathrm{~N} / \mathrm{A}$ & 28 & 15 & 51 & 34 \\
\hline Barcelona & 7 & 5 & N/A & 11 & 31 & 20 & 13 & 8 & 12 & 9 & $\mathrm{~N} / \mathrm{A}$ & $\mathrm{N} / \mathrm{A}$ & 5 & 20 & 9 \\
\hline Burgos & 34 & 32 & 5 & 15 & 23 & 17 & 27 & 2 & 7 & 33 & 19 & $\mathrm{~N} / \mathrm{A}$ & 17 & 11 & 31 \\
\hline Cádiz & 28 & 38 & 51 & 33 & 35 & 45 & 46 & 27 & 49 & 38 & 26 & 37 & 20 & 54 & 40 \\
\hline Cantabria & 47 & 49 & 28 & 20 & 36 & 49 & 48 & 35 & 43 & 57 & 24 & 25 & 18 & 60 & 33 \\
\hline Carlos III & 48 & 47 & 32 & 40 & 49 & 36 & 44 & 12 & 36 & 43 & $\mathrm{~N} / \mathrm{A}$ & 12 & $\mathrm{~N} / \mathrm{A}$ & 18 & 44 \\
\hline Castilla-La M ancha & 30 & 27 & 25 & 29 & 13 & 44 & 25 & 21 & 36 & 44 & 16 & 19 & 26 & 47 & 17 \\
\hline Complutense de M adrid & 4 & 9 & 27 & 4 & 33 & 28 & 37 & 5 & 11 & 13 & $\mathrm{~N} / \mathrm{A}$ & 5 & 19 & 24 & 25 \\
\hline Córdoba & 27 & 42 & 50 & 22 & 39 & 47 & 41 & 51 & 40 & 55 & 22 & 16 & 44 & 53 & 30 \\
\hline La Coruña & 37 & 43 & 19 & 9 & 15 & 34 & 49 & 44 & 44 & 45 & 25 & 40 & 11 & 36 & 17 \\
\hline Extremadura & 20 & 29 & 16 & 42 & 22 & 43 & 33 & 26 & 42 & 41 & 7 & 29 & 36 & 45 & 27 \\
\hline Girona & 19 & 19 & 17 & 52 & 14 & 11 & 42 & 43 & 34 & 35 & $\mathrm{~N} / \mathrm{A}$ & 31 & 23 & 15 & 14 \\
\hline Granada & 14 & 18 & 29 & 26 & 40 & 30 & 30 & 37 & 28 & 48 & 21 & 44 & 37 & 44 & 26 \\
\hline Huelva & 38 & 37 & 39 & 7 & 28 & 42 & 15 & 31 & 41 & 30 & $\mathrm{~N} / \mathrm{A}$ & 22 & 3 & 39 & 38 \\
\hline Islas Baleares & 24 & 14 & 53 & 57 & 46 & 31 & 16 & 47 & 26 & 32 & $\mathrm{~N} / \mathrm{A}$ & $\mathrm{N} / \mathrm{A}$ & 24 & 50 & 8 \\
\hline Jaén & 41 & 44 & 42 & 10 & 44 & 18 & 17 & 28 & 38 & 50 & 20 & 34 & 32 & 17 & 39 \\
\hline Jaumel deCastellón & 35 & 20 & 8 & 31 & 48 & 2 & 29 & 13 & 19 & 26 & $\mathrm{~N} / \mathrm{A}$ & 10 & $\mathrm{~N} / \mathrm{A}$ & 10 & 4 \\
\hline La Laguna & 13 & 16 & 10 & 24 & 42 & 16 & 23 & 30 & 35 & 11 & 10 & 10 & 4 & 19 & 22 \\
\hline LaRioja & 46 & 36 & 21 & 51 & 43 & 27 & 35 & 39 & 2 & 19 & $\mathrm{~N} / \mathrm{A}$ & 6 & 22 & 16 & 23 \\
\hline León & 10 & 15 & 7 & 21 & 34 & 13 & 22 & 14 & 15 & 34 & 2 & 43 & 33 & 30 & 16 \\
\hline Lleida & 21 & 21 & 9 & 8 & 21 & 25 & 24 & 45 & 4 & 12 & 4 & 9 & 6 & 28 & 43 \\
\hline Málaga & 45 & 41 & 54 & 48 & 32 & 23 & 18 & 16 & 45 & 47 & 23 & 33 & 40 & 32 & 12 \\
\hline M iguel H ernández de Elche & 57 & 52 & 4 & 35 & 55 & 48 & 53 & 32 & 5 & 56 & $\mathrm{~N} / \mathrm{A}$ & 4 & $\mathrm{~N} / \mathrm{A}$ & 59 & 46 \\
\hline Murcia & 31 & 26 & 48 & 44 & 51 & 29 & 32 & 36 & 47 & 52 & 30 & 46 & 42 & 52 & 29 \\
\hline O viedo & 29 & 22 & 18 & 36 & 41 & 4 & 34 & 15 & 23 & 24 & 18 & 3 & 30 & 29 & 19 \\
\hline Pablo de 0 lavide & 9 & 4 & $\mathrm{~N} / \mathrm{A}$ & $\mathrm{N} / \mathrm{A}$ & 19 & 54 & 1 & 50 & $\mathrm{~N} / \mathrm{A}$ & 40 & $\mathrm{~N} / \mathrm{A}$ & $\mathrm{N} / \mathrm{A}$ & 31 & 56 & 24 \\
\hline País Vasco & 25 & 23 & 40 & 19 & 30 & 14 & 36 & 17 & 18 & 25 & 9 & 20 & 14 & 41 & 10 \\
\hline Las Palmas & 42 & 45 & 24 & 25 & 24 & 39 & 45 & 42 & 22 & 36 & 29 & 32 & 13 & 14 & 11 \\
\hline Politécnica de Cataluña & 63 & 63 & 33 & 37 & 56 & 58 & 57 & 55 & 51 & 61 & 14 & 38 & 43 & 61 & 42 \\
\hline Politécnica de M adrid & 62 & 62 & 11 & 16 & $\mathrm{~N} / \mathrm{A}$ & 63 & 55 & 54 & 50 & 60 & 11 & 27 & $\mathrm{~N} / \mathrm{A}$ & 42 & 45 \\
\hline Politécnica de Valencia & 60 & 61 & 20 & 14 & 9 & 37 & 54 & 52 & 48 & 59 & 15 & 24 & $\mathrm{~N} / \mathrm{A}$ & 55 & 35 \\
\hline Pompeu Fabra & 12 & 6 & 3 & $\mathrm{~N} / \mathrm{A}$ & 53 & 6 & 21 & 33 & 29 & 42 & $\mathrm{~N} / \mathrm{A}$ & 15 & 45 & 43 & 6 \\
\hline Pública de N avarra & 33 & 40 & 14 & 12 & 16 & 35 & 47 & 20 & 13 & 15 & $\mathrm{~N} / \mathrm{A}$ & 13 & 2 & 7 & 3 \\
\hline ReyJuan Carlos & 36 & 39 & 36 & 1 & 52 & 59 & $\mathrm{~N} / \mathrm{A}$ & $\mathrm{N} / \mathrm{A}$ & $\mathrm{N} / \mathrm{A}$ & 2 & 12 & $\mathrm{~N} / \mathrm{A}$ & $\mathrm{N} / \mathrm{A}$ & 2 & $\mathrm{~N} / \mathrm{A}$ \\
\hline Rovira i Virgili & 23 & 12 & 38 & 27 & 20 & 7 & 20 & 4 & 7 & 39 & $N / A$ & 45 & 7 & 46 & 1 \\
\hline Salamanca & 11 & 11 & 22 & 5 & 26 & 10 & 6 & 3 & 17 & 21 & 13 & $\mathrm{~N} / \mathrm{A}$ & 21 & 27 & 32 \\
\hline Santiago & 3 & 3 & 1 & 3 & 17 & 3 & 9 & 25 & 20 & 23 & $\mathrm{~N} / \mathrm{A}$ & 30 & 9 & 33 & 28 \\
\hline Sevilla & 43 & 35 & 26 & 34 & 47 & 22 & 31 & 41 & 10 & 51 & 8 & 42 & 38 & 49 & 37 \\
\hline U.N.E.D. & 53 & 51 & 45 & 54 & $N / A$ & 57 & 52 & 46 & 33 & 6 & $N / A$ & 16 & $\mathrm{~N} / \mathrm{A}$ & 5 & 15 \\
\hline Valencia (Est. General) & 2 & 2 & 55 & 30 & 29 & 9 & 10 & 9 & 27 & 28 & $\mathrm{~N} / \mathrm{A}$ & $\mathrm{N} / \mathrm{A}$ & 34 & 48 & 7 \\
\hline Valladolid & 26 & 33 & 6 & 13 & 27 & 40 & 40 & 10 & 16 & 18 & 3 & 14 & 25 & 23 & 13 \\
\hline Vigo & 16 & 30 & 13 & 38 & 37 & 15 & 19 & 24 & 31 & 37 & 6 & 36 & 35 & 12 & 2 \\
\hline Zaragoza & 32 & 34 & 31 & 32 & 25 & 24 & 39 & 18 & 6 & 17 & 5 & 21 & 10 & 37 & 21 \\
\hline
\end{tabular}


Tabla 5 (cont.)

Ordenación de las universidades según los indicadores defeminización

\begin{tabular}{|c|c|c|c|c|c|c|c|c|c|c|c|c|c|c|c|}
\hline Universidades & MEN & MES & MET & MTS & MEE & MEF & MEC & MED & MDO & MPR & MPT & MPS & MPE & MPF & MCA \\
\hline Alfonso X El Sabio & 54 & 57 & 52 & 49 & 57 & 55 & 3 & $\mathrm{~N} / \mathrm{A}$ & $\mathrm{N} / \mathrm{A}$ & 1 & $\mathrm{~N} / \mathrm{A}$ & 2 & $\mathrm{~N} / \mathrm{A}$ & 1 & $\mathrm{~N} / \mathrm{A}$ \\
\hline Antonio deN ebrija & 58 & 58 & 57 & 53 & 61 & 56 & 58 & $\mathrm{~N} / \mathrm{A}$ & $\mathrm{N} / \mathrm{A}$ & 8 & $\mathrm{~N} / \mathrm{A}$ & 7 & $\mathrm{~N} / \mathrm{A}$ & 6 & $\mathrm{~N} / \mathrm{A}$ \\
\hline Católica S. Antonio de M urcia & 52 & 48 & 35 & $\mathrm{~N} / \mathrm{A}$ & 12 & 62 & $\mathrm{~N} / \mathrm{A}$ & 53 & $N / A$ & 27 & $\mathrm{~N} / \mathrm{A}$ & $N / A$ & $\mathrm{~N} / \mathrm{A}$ & 31 & $\mathrm{~N} / \mathrm{A}$ \\
\hline Católica de Avila & 61 & 59 & 44 & 2 & 59 & 53 & $\mathrm{~N} / \mathrm{A}$ & $\mathrm{N} / \mathrm{A}$ & $\mathrm{N} / \mathrm{A}$ & 4 & $N / A$ & $N / A$ & $\mathrm{~N} / \mathrm{A}$ & 8 & $\mathrm{~N} / \mathrm{A}$ \\
\hline Deusto & 6 & 7 & 15 & 17 & 2 & 5 & 8 & 23 & 3 & 20 & $\mathrm{~N} / \mathrm{A}$ & $\mathrm{N} / \mathrm{A}$ & 8 & 34 & $\mathrm{~N} / \mathrm{A}$ \\
\hline Europea de M adrid & 51 & 55 & 58 & 43 & 54 & 61 & 50 & 7 & $N / A$ & 7 & $N / A$ & 16 & $\mathrm{~N} / \mathrm{A}$ & 4 & $\mathrm{~N} / \mathrm{A}$ \\
\hline Internal. de Cataluña & 44 & 46 & $\mathrm{~N} / \mathrm{A}$ & 6 & 11 & 60 & $N / A$ & 49 & $\mathrm{~N} / \mathrm{A}$ & 53 & $\mathrm{~N} / \mathrm{A}$ & 23 & $N / A$ & 38 & $\mathrm{~N} / \mathrm{A}$ \\
\hline M ondragón & 59 & 60 & 41 & 55 & 1 & 12 & 56 & 57 & $\mathrm{~N} / \mathrm{A}$ & $\mathrm{N} / \mathrm{A}$ & $\mathrm{N} / \mathrm{A}$ & $\mathrm{N} / \mathrm{A}$ & $\mathrm{N} / \mathrm{A}$ & $\mathrm{N} / \mathrm{A}$ & $\mathrm{N} / \mathrm{A}$ \\
\hline Navarra & 17 & 24 & 2 & 18 & 3 & 26 & 28 & 22 & 39 & 16 & $\mathrm{~N} / \mathrm{A}$ & 26 & 1 & 21 & $\mathrm{~N} / \mathrm{A}$ \\
\hline 0 berta de Catal unya & 56 & 56 & 56 & $\mathrm{~N} / \mathrm{A}$ & 60 & 33 & 4 & $\mathrm{~N} / \mathrm{A}$ & $\mathrm{N} / \mathrm{A}$ & $\mathrm{N} / \mathrm{A}$ & $\mathrm{N} / \mathrm{A}$ & $\mathrm{N} / \mathrm{A}$ & $\mathrm{N} / \mathrm{A}$ & $\mathrm{N} / \mathrm{A}$ & $\mathrm{N} / \mathrm{A}$ \\
\hline Pontificia de Comillas & 49 & 50 & 49 & 46 & 5 & 50 & 51 & 38 & 21 & 54 & $N / A$ & 35 & 39 & 26 & $\mathrm{~N} / \mathrm{A}$ \\
\hline Pontificia de Salamanca & 55 & 54 & 47 & 56 & 18 & 51 & 14 & 48 & 32 & 58 & 27 & $\mathrm{~N} / \mathrm{A}$ & 46 & 58 & $\mathrm{~N} / \mathrm{A}$ \\
\hline Ramón Llull & 22 & 13 & 43 & 28 & 6 & 32 & 5 & 56 & 46 & 46 & 1 & 41 & 16 & 57 & $\mathrm{~N} / \mathrm{A}$ \\
\hline SEK & 50 & 53 & 30 & 23 & 50 & 21 & N/A & $\mathrm{N} / \mathrm{A}$ & $N / A$ & 10 & $N / A$ & $N / A$ & $N / A$ & 13 & $\mathrm{~N} / \mathrm{A}$ \\
\hline San Pablo-CEU & 40 & 28 & $\mathrm{~N} / \mathrm{A}$ & $\mathrm{N} / \mathrm{A}$ & 58 & 52 & 43 & 34 & 1 & 5 & $N / A$ & $\mathrm{~N} / \mathrm{A}$ & $\mathrm{N} / \mathrm{A}$ & 9 & $\mathrm{~N} / \mathrm{A}$ \\
\hline Vic & 1 & 1 & 12 & $\mathrm{~N} / \mathrm{A}$ & 8 & 1 & 2 & 1 & $N / A$ & 3 & $N / A$ & 1 & 28 & 3 & $\mathrm{~N} / \mathrm{A}$ \\
\hline $\mathrm{N}$ & 63 & 63 & 58 & 57 & 61 & 63 & 58 & 57 & 51 & 61 & 30 & 46 & 46 & 61 & 46 \\
\hline
\end{tabular}

Nota: Los datos referentes a catedráticos sólo se publican para universidades públicas.

do y M PR mujeres profesoras. Esto se debe en parte al hecho, ya sugerido, de que antes de terminar el doctorado muchas mujeres son ya profesoras en la misma universidad donde realizan (o van a realizar) el doctorado. Puede que esas mujeres aparezcan al mismo tiempo en las dos estadísticas: como doctorandas y como profesoras. Esta pauta endogámica es un peligro para la excelencia de las universidades. Es negativa a nivel de mujeres, y también a nivel de varones. Q uizá es peor en el caso de varones debido a la concentración de poder que luego mantienen y que impide que las mujeres ocupen esos mismos espacios. Es interesante comprobar que la correlación entre doctorandas y profesoras (M ED con M PR) es 0,59, exactamente igual que entre doctoras y profesoras (M D 0 y M PR). M CA es una variable que no se explica con estos factores, sino que depende de otros. La existencia de universidades de catedráticos varones es mucho más fácil de explicar por la tipología de «universidades de varones» (politécnicas, pontificias, privadas clásicas como D eusto y $N$ avarra) que no la estructura de «universidades de catedráticas» (que no coincide con las «universidades de profesoras» que son las privadas nuevas). Los datos muestran diversas tipologías de universidades según su proporción de mujeres en los distintos niveles. $H$ ay universidades de mujeres estudiantes, universidades de doctoras y profesoras, y universidades de catedráticas; siendo estos tres tipos de universidades distintos. Está por ver si durante este siglo XXI se puede producir el fenómeno de convergencia. Sería intere sante que los tres fenómenos se unificasen, pero es un tema com- plicado y que seguramente depende de variables múltiples como periferia, segundo empleo familiar en familias que ya son del cuerpo de funcionarios (esposo catedrático, por ejemplo), creación reciente de universidad pública, etc.

La tabla 5 presenta las universidades españolas ordenadas para cada indicador del proceso de feminización. Esta tabla permite entender mejor las peculiaridades del sistema universitario de nuestro país. No todas las bases son 63, pues hay universidades sin Escuelas Técnicas Superiores, o sin programas de doctorado en marcha, 0 incluso sin el sistema de cátedras. Pero hay datos suficientes para entender la realidad, sobre todo de universidades concretas, casi imposible con los indicadores originales.

El Gráfico 2 compara las universidades con mujeres en dos indicadores centrales: mujeres estudiantes (M ES) y mujeres profesoras (M PR). Sirve para entender los distintos tipos de universidades españolas, en relación con los procesos de feminización que están experimentando. Las universidades con más mujeres son las grandes, clásicas y en grandes ciudades. Las universidades con menos estudiantas mujeres son las que se identifican como universidades politécnicas y pontificias. En este caso su nivel bajo de mujeres viene explicado por otros factores estructurales, de desarrollo y tradición. UN ED destaca como una universidad de varones, quizás por su carácter «a distancia».El resto de las universidades de varones son las privadas; sobre todo las privadas de más reciente creación en M adrid: Alfonso X el Sabio, Anto- 


\section{Gráfico 2}

Mujeres etudiantes y profesoras

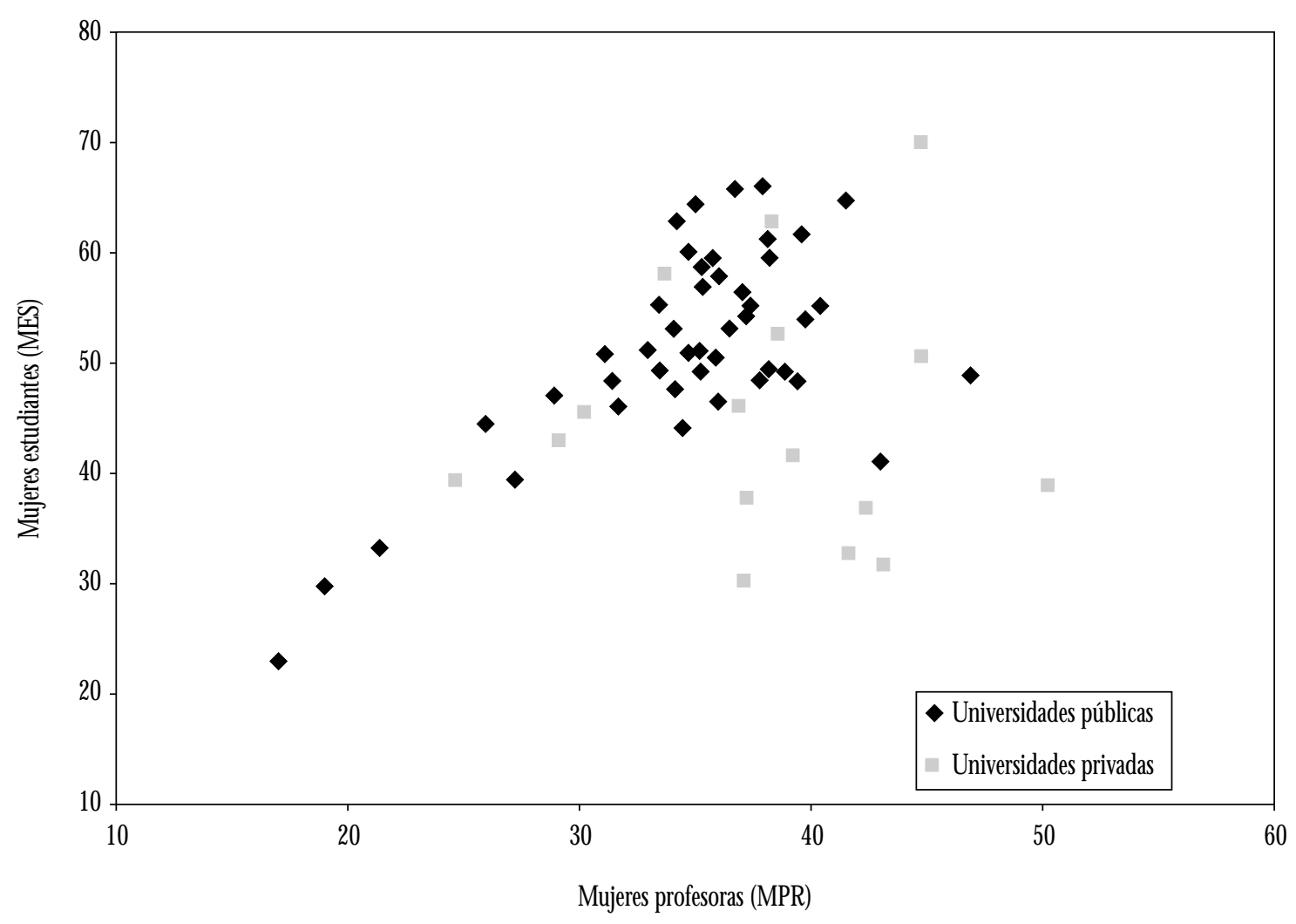

Fuente: Tabla 3.

N ota: M ES es la proporción de mujeres estudiantes, y M PR es el porcentaje de mujeres entre el profesorado. Ambas variables correlacionan 0,26. La correlación sólo para las universidades públicas es 0,68 , y para las privadas - 0,08 . Las Universidades 0 berta de $C$ atal unya y M ondragón no tienen datos para la proporción de profesoras; se les ha imputado la media de su grupo (privadas) que correspondea 37 por 100.

nio de N ebrija y Europea de Madrid. Como se observa en el gráfico, hay dos patrones distintos, uno para las universidades públicas y otro para las privadas. Mientras que la correlación entre M ES y M PR es positiva para las universidades públicas, ésta es negativa para las privadas. La homogeneidad entre universidades en relación al género no es una característica de nuestras instituciones de educación terciaria. La variable público-privado actúa como interviniente entre la relación mujeres profesoras y muje resalumnas.

La situación para el profesorado es diferente. Las universidades con muchas mujeres profesoras son algunas que tienen muchos estudiantes varones, es decir, las mismas privadas, y UN ED. La U niversidad de Barcelona - fuera de ambos contextos de privada y a distancia- es una universidad de mujeres para mujeres. Cataluña va a la cabeza en la feminización de sus universidades, tanto para alumnas, como profesoras. En esta Comunidad Autó- noma se encuentran tres 0 cuatro de las diez primeras universidades en cada grupo: Pompeu, Barcelona, Autónoma de BarceIona y Ramon Llull en cuanto a universidades para mujeres (estudiantes); y Barcelona, Lleida, Rovira i Virgili como universidades de mujeres (profesoras). Las universidades con profesorado masculino son las politécnicas, las pontificias (en este caso sólo C omillas), así como otras universidades con especialidad politécnica. La educación de las politécnicas es todavía extremadamente masculina, sobre todo en lo que se refiere a profesorado. Estando aś las cosas puede tardar varios años hasta que la proporción de los dos géneros se nivele. La situación de Politécnica de Catalunya es la más discriminante de España, pues no tiene apenas competición en el sector privado de inge niería. En cambio en Madrid se nota un progreso evidente de la educación de ingeniería/arquitectura para varones en el sector privado, por lo que la Universidad Politécnica de M adrid está 
aumentando la proporción de alumnado femenino en sus Escue las T écnicas Superiores. Se sugiere la hipótesis de que el sector privado reciente atrae alumnado masculino de clases altas y profesorado femenino (seguramente también de clases altas), detrayéndolo así del sector público. Puede haber explicaciones alternativas a la clasificación con cuatro tipos: por un lado hay universidades de profesores-varones, y universidades de profesorasmujeres, y por el otro hay universidades para estudiantes-varones, y otras para estudiantes-mujeres. Las universidades privadas recientes son universidades de profesoras y de estudiantes-varones. El personal ha sido contratado en el último lustro, y por lo tanto puede ser masculino y femenino de forma más equilibrada. D eusto y N avarra en su origen fueron universidades con personal mayoritariamente masculino, característica que aún hoy conservan ya que mucho de su profesorado se contrató hace décadas.

M ás difícil de explicar es que el alumnado de las universidades privadas más recientes sea masculino. Eso puede deberse a que está compuesto de varones que no han obtenido suficiente nota en el examen de selectividad para entrar en carreras de prestigio y que exigen una nota elevada. Dado que pertenecen a familias de clases medias-altas deciden estudiar en universidades privadas pagando. ¿Pero, por qué no lo hacen las mujeres de su clase social, sus propias hermanas? H ay dos razones. Por un lado, las mujeres sacan mejores notas en la selectividad, y por lo tanto pueden acceder a la universidad pública con esas notas. La segunda razón es porque todavía hoy las familias continúan invirtiendo más recursos en sus hijos que en sus hijas. A menudo se observa que en una misma familia el hijo acude a una universidad privada, y la hija estudia en una universidad pública. Este fenómeno ocurre más en $M$ adrid que en Barcelona, ya que en $M$ adrid hay más universidades privadas donde seguir esta opción. En M adrid el mercado ha inventado un sistema para solucionar este «problema» familiar. Eso no ocurre tanto en Barcelona, porque el mercado privado es más limitado13.

La dinámica de discriminación por género y clase social ocurre principalmente en M adrid, Barcelona, Bilbao y Pamplona. El resto de las provincias y ciudades no tienen elección posible. La universidad pública local tiene el monopolio prácticamente total sobre casi todas las personas que quieren estudiar una carrera universitaria en su provincia, independientemente de la clase social de las familias. Salvo, claro está, que una familia burguesa, de provincias, decida enviar a su hijo a estudiar a M adrid, D eusto, 0 N avarra. Las universidades nuevas, sobre todo en M adrid, cumplen así la función de que los hijos de la burguesía, algunos de ellos con notas bajas, puedan realizar una carrera de uprestigio» como ingeniería, dirección de empresas, arquitectura, o medicina (todas ellas con notas altas de entrada). M uchas de esas universidades privadas son pues una estrategia organizacional para evitar los sistemas públicos de selectividad universitaria, y sobre todo para asegurar a las familias burguesas la reproducción de su clase social. La universidad privada asegura que la mayor parte de sus estudiantes terminen la carrera en los años previstos, aprobando curso a curso. Esta estrategia reproductora del estatus social familiar no ocurre tanto en el País Vasco o en Cataluña, porque las burguesías impulsan a sus hijos e hijas a estudiar; precisamente las cualidades que permitieron a esas burguesías vasca y catalana adquirir recursos o al menos conservarlos.

El sistema de universidades privadas de M adrid cubre todo el territorio nacional, no solamente $M$ adrid. 0 frecen la posibilidad de cursar estudios de prestigio (carreras largas, aparejadas a salarios altos, y con poder) a estudiantes con malas notas (o no muy buenas), y también sirven a esos estudiantes «de provincias» para madurar en un ambiente urbano y centralista, relativamente cosmopolita, adquiriendo adicional mente contactos profesionales y personales que les van a servir luego durante toda su vida. $\mathrm{Ob}$ viamente Barcelona y Bilbao no cumplen esas funciones para toda España, sino dentro de su entorno autonómico que es bastante más reducido. Pero los sistemas de selección tanto en D eusto como en Navarra son estrictos, y el alumnado es escogido de forma relativamente rigurosa, y por lo tanto es un contexto un poco más femenino que la media. Como en el resto de las universidades privadas el alumnado de esas dos universidades va aprobando los cursos en el tiempo reglamentario. Con el avance de las universidades públicas paralelas - U niversidad del País Vasco y Universidad de N avarra - las dinámicas universitarias de N avarra y el País Vasco están cambiando año a año. Todas las afirmaciones de los últimos párrafos son hipótesis sociológicas, pues todavía no hay datos que permitan demostrarlas. En ese sentido son imaginativas, arriesgadas, y para establecerlas deben ser demostradas en el futuro.

España ha pasado en menos de medio siglo de ofrecer una educación terciaria exclusiva para grupos privilegiados a ofrecer una educación que al canza la mayor parte de la cohorte de jóvenes españoles. España tien de a un modelo universalizador de la Universidad. Sin embargo, una mirada exhaustiva a las cifras oficiales demuestran que aún existen desigualdades. El Anteproyecto de Ley O rgánica de U niversidades (2001) no tiene en cuenta el proceso de feminización. En este artículo se han analizado las diferencias por género en la U niversidad española. A nivel de estudiantes estas diferencias son en las especialidades elegidas, y en el descenso de la proporción de mujeres a medida que se escala en la jerarquía universitaria. Las mujeres están infrarrepresentadas en las Escuelas T écnicas Superiores, especialmente en ingenierías y Arquitectura. Están sobrerrepresentadas en H umanidades y algunas especialidades en Escuelas U niversitarias. Las mujeres son mayoría a la hora de graduarse, pero no lo son en estudios de postgrado.

A nivel de profesorado se evidencia la falta de mujeres en todas las especialidades y a todos los niveles, tanto en profesorado joven y con contratos precarios como en profesoras con puestos 
consolidados: titulares o catedráticas. Para llegar a un nivel de no-discriminación hay que pasar de 34 por 100 de mujeres en el profesorado a 50 por 100. La proporción actual de mujeres-profesoras (M PR) oculta una situación discriminante sobre el poder que las mujeres ocupan en la universidad (MCA) y que ocurre incluso en universidades que tienen un nivel alto en la proporción de mujeres-profesoras. La relación entre la feminización del estudiantado y del profesorado es positiva, pero no muy alta $(0,30)$. Q ue una universidad concreta tenga estudiantes mujeres no supone que también tenga profesoras, ni viceversa. M ás bien se observa una convergencia hacia una situación de equilibrio con 53 por 100 de estudiantas y 34 por 100 de profesoras.

M aría Antonia García de León y M aría García de CortáZAR acaban de publicar un libro en el que vuelven a denunciar la posición desventajosa en la que se encuentran las mujeres en la universidad española (2001). Su objetivo en este volumen, que cuenta con la contribución de varias especialistas en el tema de género, es evidenciar los mecanismos del poder académico que tienen un efecto discriminatorio por género. Según estas autoras, este efecto discriminatorio tiene incluso un rechazo previo, es de cir, que las mujeres se autoeliminan de las redes de poder. GARCía Y G ARCía corroboran con su estudio cualitativo las hipótesis presentadas en este artículo, que la mujer se va encontrando obstáculos cada vez más difíciles de superar, desde que entra en la carrera, hasta que obtiene la posición de profesora, o catedrática.

España presenta diferentes pautas de feminización en sus universidades. Es posible descubrir tendencias explicables por la naturaleza de la universidad, sus especialidades, localización geográfica, etc. La mayoría de las universidades tienen más mujeres estudiando en sus aulas, pero no ocurre así con las profesoras en que la tendencia es menos clara. Como se puede observar en el Gráfico 2 hay una cola por ambas partes que parece frenar el de sarrollo de ambos procesos de feminización. Lo más destacable es la existencia de universidades de varones-para-varones. Estas son las tres politécnicas, en el extremo inferior derecho. Un poco más arriba pero todavía siendo universidades de profesores-varones para estudiantes-varones, están las dos pontificias. Arriba a la izquierda están todas las privadas y recientes: Alfonso X, Europea de M adrid y N ebrija. La mayoría de las universidades públicas están en el cuadrante superior derecho, es decir, son universidades de mujeres estudiantes y profesoras. Allí están también, adoptando una pauta casi pública, las universidades privadas de D eusto y N avarra. Es curioso que de las cuatro posibilidades lógicas, el cuadrante de universidades de profesores-varones para estudiantas apenas tiene casos. El proceso de feminización es bastante similar en todas las universidades, con la excepción de unos casos periféricos que son las politécnicas, pontificias, y privadas recientes. El resto se agrupa en una tendencia hacia un exceso de estudiantas y una escasez de profesoras.

La Universidad española actual, y la edad durante la que se realizan los estudios universitarios, son el entorno institucional y la época vital en que la discriminación por género es menor. Las mujeres que estudian en la universidad son en su mayoría jóvenes y viven su «mejor» época de no-discriminación. La torre de marfil que todavía representa la U niversidad oculta procesos de discriminación que afectan otras esferas, sobre todo al mercado de trabajo. Una vez que las mujeres terminan sus estudios es cuando se evidencia que la «vida real» (léase mercado de trabajo y vida familiar) es progresivamente más discriminatoria para las mujeres. D entro de la Universidad, el doctorado, la carrera docente, sobre todo la cátedra, así como el poder dentro de la Universidad, está en manos de varones. Las políticas para erradicar esta discriminación no deben actuar únicamente sobre la esfera universitaria.

Como Charles y BRAdLey (2000) muestran en su estudio, las variables a las que los investigadores deben prestar atención en el estudio de las desigualdades son la penetración de normasy estructuras de género igualitarias, las características del sistema de educación nacional y del mercado de trabajo, las cuales pueden afectar de forma independiente en las desigualdades. España mantiene una historia donde la discriminación en el mercado de trabajo tiene todavía una influencia destacable, y en donde la familia ha servido (y sirve todavía) para reproducir estereotipos masculinos. La entrada masiva de la mujer en la U niversidad, independientemente del área de estudio que elija, contribuye a eliminar sólo parte de las desigualdades de género.

Notas

* D epartment of Sociology, University of Pennsylvania. Vaquera@sas.upenn.edu. ** Catedrático de Sociología, Universitat de Barcelona. European Cooperation in the Field of Scientific and Technical Research. Prince of Asturias Chair, Georgetown University. D emigue@@eco.ub.es.

1 Jordi Cails y Raül Tormos colaboraron en la realización de la investigación original de este artículo. También queremos agradecer a Sonia Frías, M arga M arí-K Iose, Carmen D omínguez Alcón y Josep A. Rodríguez las ideas para mejorar el estudio. Xavier Escandell, Pau M arí-Klose y Diego Torrente contribuyeron también con sugerencias. 2 Los objetivosy definición de la U niversidad universal se presentan en «T he universal university», de Federico M ayor Zaragoza, Higher Education Policy 11 (1998), págs. 249-255. M ayor Zaragoza es el antiguo Director de la Unesco.
3 Esel primer año parael queseha encontrado información quediferencia por géneros. M inisterio delnstrucción Públicay Bellas Artes, Anuario Esadísico deEspaña: AñoVII (1920), (M adrid: D irección General del Instituto Geográfico y Estadístico (1922), 466 pág.

4 Según los últimos datos publicados por el Instituto N acional de Estadística. H ttp://www. ine.es/inebase/cgi/um (26 de septiembre de 2002).

5 Véase «N uevas formas familiares» (págs. 442-455) en el capítulo sobre «Sistemas de reproducción social, en el libro de Jesús M. de M IGUEL, Estructura y cambio social en España (1998).

6 Un estudio financiado por el Instituto de la M ujer es el de M arisa G ARCíA C ORTÁZAR y M aría A. GARCíA DE LEÓN, M ujeresen minoría: U na investigación sociológica sobre las catedráticas de universidad en España (1997). 
7 Las estadísticas oficiales por universidades que proporciona el Instituto Nacional deEstadística no diferencian estos dos grupos (catedráticas de Escuela Universitaria, y catedrá ticas de Universidad). Es un inconveniente para interpretar la información estadística, pero no existe otra fuente oficial que proporcione estos datos desagregados en dos grupos. 8 Recomendamos la consulta del libro de Emilio J. CASTILLA, Análisis dinámico (1999).

${ }^{9} \mathrm{H}$ abría que realizar un análisis de cohortes, pero los datos oficiales que existen actualmente en España son insuficientes. Conviene seguir una misma cohorte a lo largo del tiempo. Un intento cualitativo por cohortes lo realizamos en el libro La sociedad transversal (DE M Iguel, Castilla, y CAïs, 1995). Un estudio de itinerarios vitales, también a consultar, es el de M arga M ARí-KLOSE y Anna N os (1999).
10 Es una encuesta postal, y de la muestra original de 555 catedráticas logran obtener datos de 254, es decir, 46 por 100. Es una proporción baja, pero las autoras demuestran que el colectivo final posea características similares al universo, por lo que los datos es posible que sean bastante representativos.

11 Incluyen un breve análisis del Consejo Superior de Investigaciones Científicas (CSIC).

12 Todos los datos están cal culados sobre las estadísticas oficiales que mezclan «catedrático de universidad» con «catedrático de escuela universitaria».

13 En Barcelona ocurre como en Bilbao (D eusto) o Pamplona (N avarra) en donde el sector universitario privado es incluso más selectivo que el sector público. Por eso en estas universidades privadas hay más estudiantes mujeres que varones.

\section{Bibliografía}

Anteproyecto de Ley 0 rgánica de U niversidades (M adrid: M inisterio de Educación, Cultura, y D eporte, 2001), 156 artículos.

Alberdı, Inés, La nueva familia española (M adrid: Taurus, 1999).

AltbaCH, Philip G., «Comparative perspectives on higher education for the twentyfirst century», Higher Education Policy 11 (1998) págs. 347-356.

CAstilla, Emilio ) ., Análisis dinámico (M adrid: Centro de Investigaciones Sociológicas, 1998), es el número 25 de la colección Cuadernos M etodológicos.

ChaRLeS, M aria y Karen BRADLEY, «G lobal norms and national structures: Understanding gender stratification in higher education» (en prensa, 2000), 35 págs.

Charles, M aria y Karen BRADLEY, «Equal but separate? A cross-national study of sex segregation in higher education», American Sociological Review 67 (2002) págs. 573599.

El M undo, «Los mejores centros universitarios», D ocumentos, martes 29 de mayo de 2001. www.el-mundo.es/aula/50carreras/ (11 junio 2001).

García de Cortázar, Marisa, y María A. García de León, Mujeres en minoría: Una investigación sociológica sobre las catedráticas de U niversidad en España (M adrid: Centro de Investigaciones Sociológicas, 1997), 88 págs. Es el número 16 de la colección 0 piniones y Actitudes. D atos de una encuesta a 245 catedráticas en 1995.

García de Cortázar, M arisa, y María A. García de León, Las académicas. Profesorado universitario y género (M adrid: Instituto de la M ujer, 2001), 623 págs.

GIDDENS, Anthony, Un mundo desbocado (M adrid: Taurus, 2000), 117 págs.

Instituto N aCional de Estadística, Estadística dela enseñanza superior en España. Series de todos los niveles. Curso 1996-1997 (M adrid: INE, 1999), publicaciones electrónicas (disquete).

Instituto N aCional de Estadistica, Estadística dela enseñanza superior en España. Series de todos los niveles Curso 1998-1999 (M adrid: INE, 2001), publicaciones electrónicas (disquete).
JACOBS, Jerry A. «Gender inequality and higher education», Annual Review of Sociology 22 (1996), págs. 153-185.

JACOBS, Jerry A. «G ender and the stratification of colleges», Journal of Higher Education 70 (1999), págs. 161-187.

M ARí-KLOSE, M arga y Anna N OS, Itinerarios vitales. Educación, trabajo y fecundidad de las mujeres (M adrid: Centro de Investigaciones Sociológicas, 1999), 123 págs. Es el número 27 de la colección 0 piniones y Actitudes.

Mayor Zaragoza, Federico «The universal university», Higher Education Policy 11 (1998), págs. 249-255.

M Iguel, Jesús M . de, Estructura y cambio social en España (M adrid: Alianza, 1998), 681 págs.

M IGUEL, Jesús M. de, «Reinventando la Universidad», Revista Gestión y Análisis de Políticas Públicas 17-18 (2000), págs. 119-157.

M Iguel, Jesús M . de, Emilio J. Cast ILla y Jordi Caïs, La sociedad transversal (BarceIona: Fundación La Caixa, 1994), 312 págs.

M Iguel, Jesús M. de, Jordi Caïs y Elizabeth VAQUera, «M odelo de indicadores de calidad de las universidades», Revista Gestión y Análisis de Políticas Públicas 16-17 (1999), págs. 29-62.

M inisterio de Instrucción Pública y Bellas Artes, Anuario Estadístico de España: Año VII (1920), Dirección General del Instituto G eográfico y Estadístico (M adrid 1922), 466 págs.

Organisation for ECONOMIC COOPERATION AND DEVELOPMENT, Education at a Glance OECD Education D atabase (París: OECD, 2000). Incluye un CD con las estadísticas, y los manuales Classifying Educational Programmes. M anual for ISCED-97 Implementation for OECD Countriesy U ser's Guide.

UnEsCO, Statistical Yearbook 1999 (París: Unesco Publishing \& Bernan Press, 1999), 840 págs. 